\title{
A realistic large-scale model of the cerebellum granular layer predicts circuit spatio-temporal filtering properties
}

\author{
Sergio Solinas ${ }^{1,2}$, Thierry Nieus $^{3}$ and Egidio D'Angelo ${ }^{1,2 *}$ \\ 1 Department of Physiology, University of Pavia and Consorzio Nazionale Interuniversitario per le Scienze Fisiche della Materia, Pavia, Italy \\ 2 Brain Connectivity Center, Istituto Neurologico IRCCS fondazione C. Mondino, Pavia, Italy \\ ${ }^{3}$ Neuroscience and Brain Technology, Italian Institute of Technology, Genova, Italy
}

\section{Edited by:}

James M. Bower, University of Texas at

San Antonio, USA

\section{Reviewed by:}

Fidel Santamaria, University of Texas at San Antonio, USA

James M. Bower, University of Texas at San Antonio, USA

*Correspondence:

Egidio D'Angelo, Department of Physiology, University of Pavia, Via Forlanini 6, 27100 Pavia, Italy. e-mail:dangelo@unipv.it
The way the cerebellar granular layer transforms incoming mossy fiber signals into new spike patterns to be related to Purkinje cells is not yet clear. Here, a realistic computational model of the granular layer was developed and used to address four main functional hypotheses: centersurround organization, time-windowing, high-pass filtering in responses to spike bursts and coherent oscillations in response to diffuse random activity. The model network was activated using patterns inspired by those recorded in vivo. Burst stimulation of a small mossy fiber bundle resulted in granule cell bursts delimited in time (time windowing) and space (center-surround) by network inhibition. This burst-burst transmission showed marked frequency-dependence configuring a high-pass filter with cut-off frequency around $100 \mathrm{~Hz}$. The contrast between center and surround properties was regulated by the excitatory-inhibitory balance. The stronger excitation made the center more responsive to $10-50 \mathrm{~Hz}$ input frequencies and enhanced the granule cell output (with spikes occurring earlier and with higher frequency and number) compared to the surround. Finally, over a certain level of mossy fiber background activity, the circuit generated coherent oscillations in the theta-frequency band. All these processes were fine-tuned by NMDA and GABA-A receptor activation and neurotransmitter vesicle cycling in the cerebellar glomeruli. This model shows that available knowledge on cellular mechanisms is sufficient to unify the main functional hypotheses on the cerebellum granular layer and suggests that this network can behave as an adaptable spatio-temporal filter coordinated by theta-frequency oscillations.

Keywords: spatio-temporal dynamics, cerebellar cortex, neural networks, granular layer, electrophysiological modeling NMDA receptors, GABA receptors

\section{INTRODUCTION}

The cerebellum, owing to its regular structure, has inspired several theoretical models emphasizing the combinatorial properties of the network (Marr, 1969; Albus, 1971; Tyrrell and Willshaw, 1992; Dean et al., 2010). More recently, simplified spiking models have also been developed (Maex and De Schutter, 1998; Medina and Mauk, 2000). Here, by taking advantage of recent advances in single cell and granular layer circuit physiology, a new computational model is developed that incorporates a much higher level of realism than previously possible. The model has then been used to investigate granular layer spatio-temporal dynamics and evaluate the main functional hypotheses suggested by biological investigations.

In brain slices, intracellular recordings have provided a detailed understanding of membrane and synaptic properties of single neurons (among others D’Angelo et al., 1995; Dieudonné, 1998; Forti et al., 2006; see also below), while multi-electrode array (MEA) and voltage-sensitive-dye imaging (VSD) recordings have revealed relevant aspects of ensemble granular layer activities (Mapelli and D’Angelo, 2007; D’Angelo et al., 2009; Mapelli et al., 2010a,b). Recordings in vivo have shown the behavior of single granular

Abbreviations: GrC, granule cell; GoC, Golgi cell; SC/BC, stellate cell/basket cell; MLI, molecular layer interneuron; mf, mossy fiber; pf, parallel fiber. layer neurons (Vos et al., 1999; Chadderton et al., 2004; Jörntell and Ekerot, 2006; Rancz et al., 2007) and their collective activity (Roggeri et al., 2008; Courtemanche et al., 2009) in response to natural stimuli. These results have supported in turn four main functional hypotheses. (1) The granular layer response to mossy fiber bursts should be spatially organized in a center-surround pattern, where the excitatory-inhibitory balance is dominated by excitation in the center and by inhibition in the surrounding areas. (2) The granular layer should generate a time-window effect limiting the duration and intensity of the GrC output (D'Angelo and De Zeeuw, 2009). (3) The granular layer should behave as a high-pass filter allowing patterns over $50 \mathrm{~Hz}$ to be optimally transmitted (Mapelli et al., 2010). Finally, (4) sparse GrC random activity should be able to sustain coherent low-frequency oscillations of granular layer activity (Maex and De Schutter, 1998). However, whether and how these aspects integrate into a coherent functional framework has remained unclear.

Among the properties that may contribute to determine the granular layer function, some appear especially relevant. The cardinal structural properties include the glomerular organization of the mossy fiber inputs (Rossi and Hamann, 1998; Mapelli et al., 2009) and feed-forward, feed-back and lateral inhibition (Mapelli and D'Angelo, 2007; Kanichay and Silver, 2008). At 
the molecular level, special importance has been attributed to NMDA and GABA-A ( $\alpha 1$ and $\alpha 6$ subunit-containing) receptors (D’Angelo et al., 1995; Cull-Candy et al., 1998; Farrant and Nusser, 2005). These are highly sensitive to neurotransmitter spillover and are suitable to set the appropriate time constants for signal processing in the cerebellar glomerulus. Finally, neurotransmitter release probability at the $\mathrm{mf}-\mathrm{GrC}$ synapse, which can be tuned by long-term synaptic plasticity (D'Errico et al., 2009), regulates the time course of EPSP temporal summation and spike emission. Thus, these factors need to be taken into account to appropriately simulate granular layer dynamics in the spatial, temporal and frequency domains.

The computational reconstruction of the granular layer reported in this work was based on biophysically realistic models of granule cells (GrCs: D'Angelo et al., 2001; Diwakar et al., 2009) and Golgi cells (GoCs: Solinas et al., 2007a,b) and of their synapses (Nieus et al., 2006; Mapelli et al., 2009). The network, stimulated with patterns inspired to those observed in the mossy fibers (mfs) in vivo, generated center-surround, time-windowing, high-pass filtering and theta-frequency oscillations regulated by neurotransmitter release and NMDA and GABA-A synaptic receptors. Interestingly, the center-surround structure was capable of fine-tuning the delay, number, and frequency of spikes generated by GrCs suggesting that the cerebellum granular layer behaves as a complex spatio-temporal filter, which can be adapted through long-term synaptic plasticity and coordinated by coherent oscillations.

\section{MATERIALS AND METHODS}

The granular layer network structure was generated on the basis of detailed anatomical and functional information (Eccles et al., 1967; Palkovits et al., 1971, 1972; Hámori and Somogyi, 1983; Jakab and Hámori, 1988; Harvey and Napper, 1991; Korbo et al., 1993; Sultan, 2001; Barmack and Yakhnitsa, 2008) and using models of neurons and synapses including biophysical representations of membrane ionic channels and receptors (D'Angelo et al., 2001; Nieus et al., 2006; Solinas et al., 2007a,b; Diwakar et al., 2009). These neuronal and synaptic models have been extensively validated in previous works using electrophysiological and imaging data. Therefore, we have been able to develop a "realistic network model", in which the large number of parameters is constrained to biology. In this "bottom-up" approach, the functional properties of the network emerge from the properties of constitutive elements and from their synaptic organization (e.g. see Druckmann et al., 2007; Gleeson et al., 2007; Izhikevich and Edelman, 2008). The appropriateness of network responses was assessed by comparison with MEA and VSD recordings of network activity, which have recently become available for the cerebellum granular layer. Moreover, the availability of input spike patterns and neuronal responses in vivo (Vos et al., 1999; Chadderton et al., 2004; Jörntell and Ekerot, 2006; Rancz et al., 2007; Roggeri et al., 2008) has allowed to simulate granular layer network dynamics under conditions representative of natural activity states.

\section{GENERAL PROPERTIES OF THE GRANULAR LAYER MODEL}

The network had a size sufficient to reproduce a functionally relevant portion of the cerebellar granular layer, i.e. a cube with $100 \mu \mathrm{m}$ edge length (Table 1 and Figure 1). The model included 315 mfs, 4393 neurons (4096 GrCs, 27 GoCs and 270 SCs/BCs) and more than 40000 synapses. The number of cells and synapses was large enough to maintain realistic convergence/divergence ratios (Eccles et al., 1967). On this scale, $\mathrm{mf}$ branching was not implemented (see Sultan and Heck, 2003). Moreover, to achieve inhibitory control over GoCs, a partial representation of the SC/BC was also included.

Network connections were constructed using precise rules, yet allowing the number of connections and synaptic weights to show statistical variability (Gaussian distribution: mean $=1$, s.d. $=0.4$; see Medina and Mauk, 2000). No systematic differences were observed using different seeds for parameter randomization, so that in several cases the same network configuration was used to facilitate data

Table 1 |The constitutive elements of the granular layer network.

\begin{tabular}{|c|c|c|c|c|c|c|c|}
\hline & Num. & Div. & Conv. & Transmitter & Receptors & Spillover & Previous models \\
\hline Glomeruli & 315 & & & & & & \\
\hline $\mathrm{GrC}$ & 4096 & & & & & & Nieus et al., 2006 \\
\hline $\mathrm{SC} / \mathrm{BC}$ & 270 & & & & & & \\
\hline$m f \rightarrow G r C$ & & $1: 53$ & $4: 1$ & Glutamate & AMPA, NMDA & Yes & Nieus et al., 2006 \\
\hline \multirow{2}{*}{$\mathrm{GrC} \rightarrow \mathrm{GoC}(p f)$} & & & & & NMDA & Yes & \\
\hline & & & & & kainite & Yes & \\
\hline $\mathrm{GoC} \rightarrow \mathrm{GrC}$ & & $1: 600$ & $4: 1$ & GABA & GABA-A $(a 1, a 6)$ & Yes & Mapelli et al., 2009 \\
\hline$S C / B C \rightarrow G o C$ & & $1: 1$ & $6-50: 1$ & GABA & $\alpha$-function & - & This paper \\
\hline
\end{tabular}

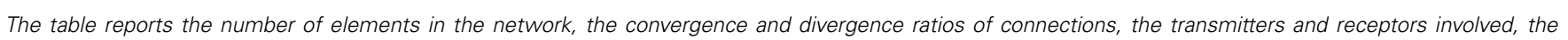

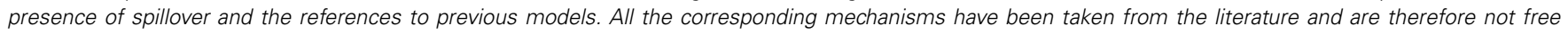
parameters but rather constitutive elements of the network. 


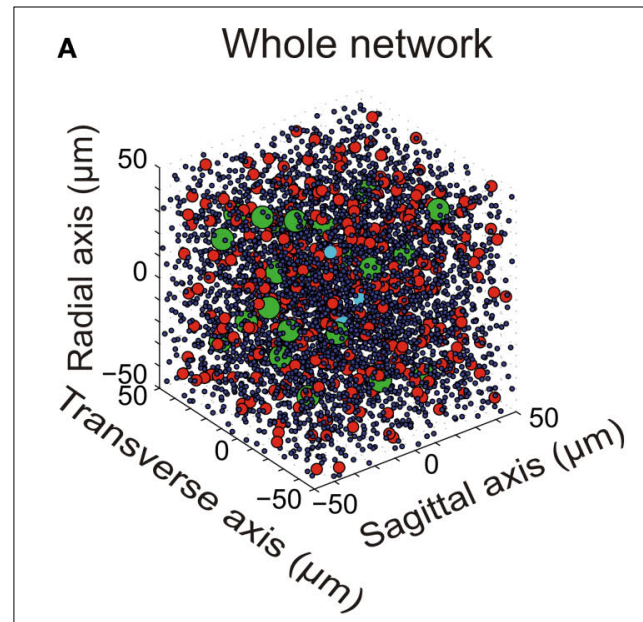

GoC $\rightarrow \mathrm{GrC}$ divergence

$\mathrm{MF} \rightarrow \mathrm{GoC}$ convergence
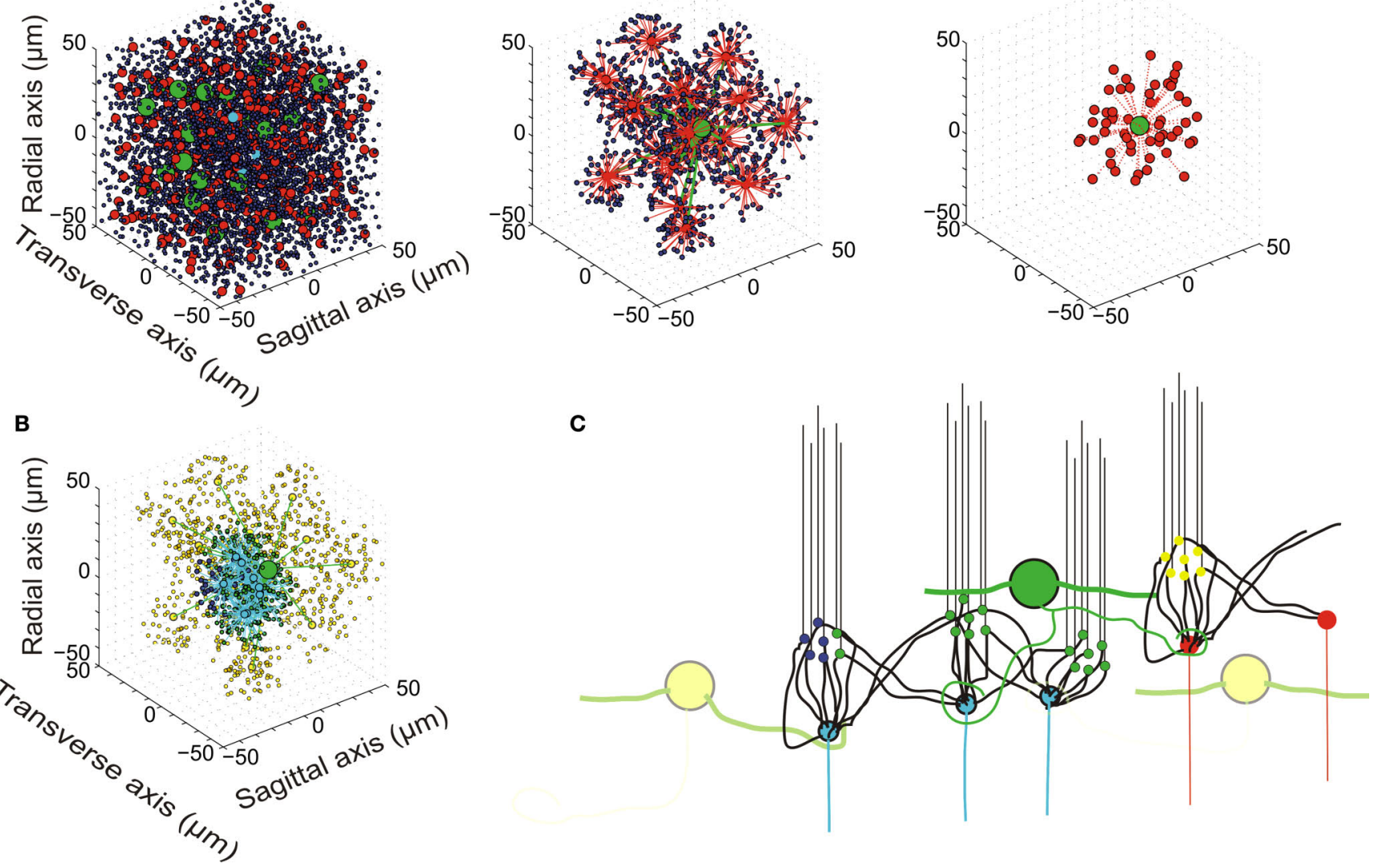

FIGURE 1 | Network topology. (A) Elements of the network. (i) The whole network: the granular layer network was simulated as a cube with edge length $100 \mu \mathrm{m}$. It contained $4096 \mathrm{GrCs}$ (blue dots), 27 GoCs (green spheres), and 315 glomeruli (red and cyan dots). The meaning of the eight glomeruli indicated with cyan dots is explained in (B). (ii) GoC-GrC divergence: the panel shows the glomeruli reached by a single $\mathrm{GoC}$ axon and $\mathrm{GrCs}$ inhibited therein. (iii) Mf-GoC convergence: The panel shows the glomeruli reaching a single GoC. Note that $\mathrm{GoC}-\mathrm{GrC}$ divergence is wider than $\mathrm{mf}-\mathrm{GoC}$ convergence, setting the basis for lateral inhibition. (B) Neurons responding to an input burst delivered to a small $\mathrm{mf}$ bundle. In this example, which is drawn from the network shown in (A), eight glomeruli represented with cyan dots were supposed to delivered a burst (five spike at $500 \mathrm{~Hz}$ ) to the network. One of the GoCs excited by the burst [the same as in (ii)] is indicated with a large green dot. The $\mathrm{GrCs}$ are indicated with small dots: $\mathrm{GrCs}$ that are only inhibited are yellow, GrCs that are only excited are blue, $\mathrm{GrCs}$ that are both excited and inhibited are green. Note that excitation is concentrated in the center and inhibition in the surround. (C) Schematic drawing of network connectivity [same color code as in (B)]. comparison. Background noise in the network was generated by random spike patterns in $\mathrm{mfs}$ and pacemaking in GoCs and SC/BCs (see e.g. Häusser and Clark, 1997; Chadderton et al., 2004; Rancz et al., 2007). Neurons and synapses were endowed with multiple receptor and ionic channel-based mechanisms, allowing an accurate representation of neuronal firing. The synapses were endowed with neurotransmitter diffusion mechanisms and with a representation of vesicle cycling, generating spillover and developing short-term facilitation and depression. However, no molecular noise (e.g. from ionic diffusion, channel gating or receptor binding) or synaptic noise (e.g. from stochastic vesicle fusion) were introduced.

The model was written with NEURON-7.1. The simulation of 3 s of activity required about $20 \mathrm{~h}$ on a Pentium- 5 dual-core but just 30 min using 80 CPUS on the CASPUR parallel cluster (http://www. caspur.it/en/). A graphical interface was written to represent the data as in MEA and VSD experiments.

\section{SPECIAL PROPERTIES OF INHIBITORY CONNECTIVITY}

The most relevant aspects of granular layer network organization depend on the inhibitory connections, which are therefore considered in detail. Lateral inhibition, as in other brain areas (Buzsáki, 2006), is an important structural property of the circuit. This has been reported since early anatomical investigations (e.g. see Eccles et al., 1967) and has recently been substantiated by electrophysiological recordings (Mapelli and D'Angelo, 2007). Lateral inhibition descended from the disproportionate extension of the GoC axon compared to its dendritic afferent field (i.e., the mossy fibers excited an area including $\mathrm{GrC}$ and $\mathrm{GoC}$ basal dendrites, but then the GoC axon redistributed inhibition over a much larger area). Two relevant aspects of the inhibitory connections, which have recently been reported in experimental investigations, have been taken into account in the model (Figure 1C). 
First, ultrastructural measurements have revealed that each $\mathrm{GrC}$ receives on average three GoC inhibitory synapses (Hámori and Somogyi, 1983), but has left open the problem on whether these synapses originated from the same or from different GoCs. Typically, GrC IPSCs can be recruited by raising stimulation intensity (Mapelli et al., 2009), suggesting that three to four independent GoCs are indeed connected. Recordings from GoC-GrC pairs further support this connectivity by showing that the size of the GoC-GrC IPSCs is equivalent to the minimal response generated by single fiber stimulation (Mapelli et al., 2009).

Secondly, since glomeruli receive about 50 dendrites from as many different GrCs, the additional issue is whether a GoC innervates all the GrCs impinging on the same glomerulus. Even minimal stimulation (i.e. one that activates a single synaptic contact) can elicit a direct and an indirect spillover-mediated component in $\mathrm{GrC}$ IPSCs (Mapelli et al., 2009). Since spillover is a sign of release on neighboring synapses in the glomerulus (Rossi and Hamann, 1998), a GoC axon should inhibit numerous (if not all) GrC dendrites in the same glomerulus.

Therefore, in addition to lateral inhibition, the GoC-GrC connections were implemented with these topological rules: a GoC was not allowed to innervate a GrC more than once (and therefore did not innervate adjacent glomeruli) and each glomerulus was fully innervated by a single GoC. In fact these rules are a simplification, since do not separate direct from indirect inhibition. An explicit representation of the glomerulus with internal diffusion allowing for independent generation of direct and indirect IPSCs may further improve this description.

\section{NETWORK ARCHITECTURE AND GENERATION OF NETWORK CONNECTIONS}

The generation of the model network occurred in three steps: (1) calculating the number of constitutive elements, (2) distributing the elements in space, and (3) connecting the elements.

(1) Starting from a GrC density of $4 \times 10^{6} / \mathrm{mm}^{3}$, the density of GoCs was calculated to be $\sim 9000 / \mathrm{mm}^{3}$ to respect the ratio 1:430 reported by Korbo et al. (1993). The density of glomeruli was calculated from the convergence/divergence ratio of the mf-GrC connections. Each glomerulus includes a mean of 53 dendrites from different $\mathrm{GrCs}$ and each $\mathrm{GrC}$ emits on average four dendrites (Jakab and Hámori, 1988). The density of glomeruli was calculated as $\left(4 \times 10^{6} / \mathrm{mm}^{3} \times 4\right.$ dendrites $) /(53$ dendrites/glomerulus $) \approx 3 \times 10^{5} / \mathrm{mm}^{3}$. Although in this network there is space for just 9 GoCs, their number was increased to 27 to compensate for the inhibitory connections that should occur in GrCs (a total of $4096 \times 4=16384$ inhibitory connections) but cannot be generated by the nine internal GoCs (providing only $600 \times 9=5400$ inhibitory connections). The missing 10984 inhibitory connections were generated by 18 additional GoCs $(10984 / 600=18)$ located outside the network but projecting their axons inside it.

(2) After having calculated the number of constitutive elements (GrCs, glomeruli and GoCs and their synapses), these were placed into the network volume with coordinates drawn from a uniform random distribution. The next step was to connect these elements together.
(3) The network connections were generated by applying simple rules, most of which can be directly extracted from original works on cerebellar architecture (e.g. see Eccles et al., 1967). (a) The GrC dendrites could not reach glomeruli farther than $40 \mu \mathrm{m}$ (mean dendritic length $13.6 \mu \mathrm{m}$ ). (b) A single $\mathrm{GrC}$ was not allowed to project more than one dendrite inside the same glomerulus. (c) Only one GoC axon was allowed to enter a glomerulus forming inhibitory synapses on all the afferent GrC dendrites. (d) A GoC axon entering into one glomerulus was prevented from accessing the neighboring glomeruli sharing GrCs with the first glomerulus. This prevented a $\mathrm{GrC}$ from being inhibited twice through the same GoC, a case that does not seem to hold experimentally (see Mapelli et al., 2009). (e) Each GoC was allowed to access at most 40 glomeruli resulting in a maximum 2000 GrCs inhibited by the same GoC. (f) GoCs received excitation from 50 glomeruli and 100 GrCs through parallel fibers (pfs) randomly selected within the network. These approximate numbers conform to existing estimates (Ito, 2006). (g) Each GoC was provided with an inhibitory input from SC/BC comprising two categories. One, equivalent to $6 \mathrm{SC} / \mathrm{BC}$, provided a background rhythmic inhibition at $18.5 \mathrm{~Hz}$ (Häusser and Clark, 1997). The inhibitory SC/ BC background activity was calibrated to balance the $\mathrm{mf}$ background activity in GoCs. The other, equivalent to 50 SC/BCs, provided dynamic inhibition through GrCs and pfs, implementing a dis-inhibitory loop. The dis-inhibitory loop was activated only to investigate network oscillations in Figure 8E and its intensity was regulated over various values.

In order to test the impact of the connectivity rules, in some modeling experiments a "mesh" configuration was used. The "mesh" was built after removing the connectivity rules $3 c$ and $3 d$ reported above, so that GoCs were connected to GrC distributed all over the network. Nonetheless, each GrC still received the same number of excitatory and inhibitory synapses. A competitive growth algorithm would be desirable in the future.

\section{IMPLEMENTATION OF NETWORK DYNAMICS}

The neuron ( $\mathrm{GrC}$ and GoC) models derived from previous models, which had been carefully tested against available experimental results in slices (D'Angelo et al., 2001; Nieus et al., 2006; Solinas et al., 2007a,b). These models were able to reproduce all the details of spike shape, timing and frequency in response to current injection and synaptic stimulation. The synaptic models were adapted from the original scheme reported by Nieus et al. (2006) and were able to reproduce the kinetics and size of the EPSCs and IPSCs during repetitive synaptic transmission at the different synapses. These models accounted for vesicular dynamics, neurotransmitter spillover and receptor gating (including multiple closed, desensitized and open states) but not for quantal release mechanisms. The dynamics of synaptic responses were fully determined by the kinetic constants of synaptic and neuronal models. Given the short distances traveled by the spikes, axonal conduction times were considered negligible. Transmission delay was $1 \mathrm{~ms}$ for all the synapses. 
In order to conform to in vivo conditions, all models had to be adapted from their original temperature $T_{\text {orig }}$ to $T_{\text {sim }}=37^{\circ} \mathrm{C}$ using the correction factor $Q_{10}{ }^{\text {(Tsim-Torig)/10 }}$ (Gutfreund et al., 1995; see also Traub and Llinas, 1979; Traub et al., 1991; Vanier and Bower, 1999). We have used: $Q_{10}=3$ for ionic channel gating, $Q_{10}=2.4$ for receptor gating, $Q_{10}=1.5$ for ionic channel permeation, $Q_{10}=1.3$ for neurotransmitter diffusion, $Q_{10}=3$ for $\mathrm{Ca}^{2+}$ pumps and buffers, $Q_{10}=1.3(\mathrm{GrC})$ or $1.7(\mathrm{GrC})$ for intracellular $\mathrm{Ca}^{2+}$ diffusion. Following adaptation at $37^{\circ} \mathrm{C}$, the models were in matching with recordings at this same temperature (data not shown). The basic properties of GrCs and GoCs embedded into the granular layer network are shown in Figures 2-4.

\section{SINGLE CELL AND SYNAPTIC MODELS}

The GrC model was adapted from Nieus et al. (2006) by applying appropriate $Q_{10}$ corrections. In addition, the GABA leakage conductance was increased by two times $\left(60 \mu \mathrm{S} / \mathrm{cm}^{2}\right)$, the Inward rectifier $\mathrm{K}^{+}$conductance was increase by 1.5 times $\left(1350 \mu \mathrm{S} / \mathrm{cm}^{2}\right)$ and the leakage reversal potential was adjusted to restoring resting potential to $-70 \mathrm{mV}$ (see D'Angelo et al., 2001). With this asset, the $\mathrm{GrC}$ model properly reproduced responses to current injection at $37^{\circ} \mathrm{C}$ (data not shown) and spike trains observed in vivo (Chadderton et al., 2004; Jörntell and Ekerot, 2006) reaching maximum firing rates as high as $500 \mathrm{~Hz}$ (see Figure 2B ). $_{1}$.

The GoC model was adapted from Solinas et al. (2007a,b) by applying appropriate $Q_{10}$ corrections.

Without needing any further change, the GoC model properly reproduced responses to peripheral stimulation observed in vivo (Vos et al., 1999) and could reach a maximum firing rate of $350 \mathrm{~Hz}$ (see Figure $2 \mathrm{~B}_{2}$ ).

The SC/BC models, in the absence of detailed computational representations, were designed as random spike generators with a basal firing of $18.5 \mathrm{~Hz}$ (Armstrong and Rawson, 1969; Häusser and Clark, 1997).

The $m f-G r C$ synapses take part to the formation of the cerebellar glomerulus, are glutamatergic and activate AMPA and NMDA receptors. The release, diffusion and ionic receptor mechanisms were the same reported by Nieus et al. (2006). Using a probability of release of 0.6 , the model was able to faithfully reproduce postsynaptic currents recorded at $37^{\circ} \mathrm{C}$ in vitro (Saviane and Silver, 2006) and in vivo (Chadderton et al., 2004; Rancz et al., 2007). The time constant of the recovery from depression, $\tau_{\mathrm{REC}}=8 \mathrm{~ms}$, was derived from in vivo measurements (Jörntell and Ekerot, 2006) and allowed to reproduce natural dynamics of short-term plasticity (the time constants of presynaptic facilitation and vesicle inactivation were set to $\tau_{\text {facil }}=5 \mathrm{~ms}$ and $\tau_{\mathrm{I}}=1 \mathrm{~ms}$, respectively).

The $m f-G o C$ synapses are similar in several respects to the mf$\mathrm{GrC}$ synapses. They are also located within the cerebellar glomerulus (Eccles et al., 1967) and are glutamatergic activating both AMPA and NMDA receptors (Kanichay and Silver, 2008; Cesana et al., 2009). The mf-GoC synapse was adapted from the $\mathrm{mf}-\mathrm{GrC}$ synapse model (see above) to reproduce a peak postsynaptic current of -66 pA (Cesana et al., 2009; see Figures 2-5). Release probability and vesicle cycling parameters were set at the same values as at the mf-GrC synapse.
The GrC-GoC synapses are formed by pfs onto GoC apical dendrites in the molecular layer (Palay and Chan-Palay, 1974). These glutamatergic synapses activate AMPA, NMDA and Kainatereceptors (Dieudonné, 1998; Bureau et al., 2000; Misra et al., 2000). During repetitive stimulation, the AMPA current shows synaptic depression while the Kainate and NMDA currents show slow temporal summation. AMPA and NMDA currents were taken from the mf-GrC synapses and the kainate receptor current was modified from the AMPA kinetic scheme. Release probability was 0.1 and vesicle cycling parameters were set at the same values as at the mf-GrC synapse.

The GoC-GrC synapses are GABAergic and impinge on GrC dendrites within the glomeruli. GABAergic neurotransmission was modeled based on Mapelli et al. (2009). The GABA-A receptor schemes comprised channels with fast $(\alpha 1)$ and slow $(\alpha 6)$ kinetics and GABA spillover generating the transient and sustained components of inhibition observed experimentally. In order to account for experimental results (Mapelli et al., 2009), the parameters describing presynaptic dynamics were: release probability $=0.35$, $\tau_{\mathrm{REC}}=36 \mathrm{~ms}, \tau_{\text {facil }}=58.5 \mathrm{~ms}$ and $\tau_{\mathrm{I}}=0.1 \mathrm{~ms}$, respectively (Mapelli et al., 2009).

The SC/BC-GoC synapses are GABAergic and impinge on the GrC apical dendrites in the molecular layer. The postsynaptic current resulting from a single spike was described by a doubleexponential function with $\tau_{1}=0.26 \mathrm{~ms}, \tau_{2}=15 \mathrm{~ms}$, and $1370 \mathrm{pS}$ maximum conductance, similar to synapses made by the same neurons onto Purkinje cells (see Jaeger et al., 1997).

\section{PATTERNS OF ACTIVITY}

The granular layer shows a background activity state, over which the $\mathrm{mf}$ inputs generate evoked responses. In brain slice recordings, $\mathrm{mfs}$ and GrCs are silent, GoCs show rhythmic spontaneous activity at around $6 \mathrm{~Hz}$ (Dieudonné, 1998; Forti et al., 2006) and SC/BCs show rhythmic spontaneous activity at around $18.5 \mathrm{~Hz}$ (Häusser and Clark, 1997). Evoked activity occurs in GrC clusters of about $30 \mu \mathrm{m}$ diameter (Mapelli et al., 2010a), which may represent granular layer functional units (Sultan and Heck, 2003). In the anesthetized rat in vivo, the mfs show a low basal activity $(<1 \mathrm{~Hz})$, GrCs generate sporadic spikes $(<0.1 \mathrm{~Hz})$ (Chadderton et al., 2004; Rancz et al., 2007), GoCs show a basal activity at $1-18 \mathrm{~Hz}$ (mean $=8.42$, numeric $\mathrm{cv}=0.43$; Vos et al., 1999) and SC/BCs show a basal activity at $47 \pm 17 \mathrm{~Hz}$ (Wang et al., 2009). Following punctuate sensory stimulation, mfs convey high-frequency bursts and GrCs and GoCs respond after short delay generating themselves short bursts at 200-300 Hz (Vos et al., 1999, 2000; Chadderton et al., 2004; Jörntell and Ekerot, 2006; Rancz et al., 2007). These responses are clustered in small areas and can be detected by measuring the corresponding local field potentials (Roggeri et al., 2008).

\section{Spontaneous activity}

Background activity in the model was generated by the following mechanisms. (i) The mfs were activated with a random spiking activity. Spike timing was drawn from a Poisson distribution (mean $=1 \mathrm{~Hz}, \mathrm{cv}_{2}=0.9$; see below for $\mathrm{cv}_{2}$ definition). (ii) GoCs were spontaneously active and their spike frequency and $\mathrm{Cv}_{2}$ matched the range reported in vivo once $\mathrm{mfs}$ and $\mathrm{SC} / \mathrm{BC}$ were made active them- 
selves. (iii) SC/BCs were endowed with a random spiking activity drawn from a Poisson distribution $($ mean $=18.5 \mathrm{~Hz}, \mathrm{cv} 2=0.9$ ). It should be noted that $\mathrm{SC} / \mathrm{BC}$ functions were critical to control the basal activity state of GoCs. When the SC/BC random activity was turned off, the GoCs showed an unnaturally high firing frequency and blocked granular layer signal processing (unpublished observations).

\section{Evoked activity}

The $\mathrm{mf}$ bursts generated by punctuate tactile stimulation are composed of 5-10 spikes with an average frequency around $100 \mathrm{~Hz}$ and instantaneous frequencies as high as $700 \mathrm{~Hz}$ in the anesthetized rat (Chadderton et al., 2004; Rancz et al., 2007). More protracted stimuli have been reported to generate longer bursts with frequencies modulated between a few $\mathrm{Hz}$ and $500 \mathrm{~Hz}$ in the behaving monkey (Kase et al., 1980) and up to $1000 \mathrm{~Hz}$ in the decerebrated cat (Jörntell and Ekerot, 2006). Evoked activity was simulated by stimulating eight contiguous unbranched mfs in the middle of the network (see Figure 1), which activated $\sim 30 \mu \mathrm{m}$ large GrC clusters. The stimuli consisted in spike bursts of different frequencies and duration, as indicated in the specific result sections (Figures 2-7), overriding the ongoing background activity.

\section{DATA ANALYSIS}

Simulation results were stored for offline analysis and processed using customized MATLAB programs (The MathWorks, Natick, MA, USA).

Single cell activities were analyzed as in ordinary patch-clamp experiments (averages of up to 150 simulations were required to overcome the irregularity generated by background network activity). The auto- and cross-correlograms (e.g. see Figure 8) were generated using data from 3-s long simulations. In order to display the average firing rate of an individual cell, the histograms were normalized by the total number of cells, by the number of stimulation spikes and by the bin width (1 ms).

Spatially organized activity was analyzed as in VSD experiments. Activity images (e.g. see Figure 5A) were reconstructed from the membrane potential of individual GrCs generating an average response within a volume. The peak of the cumulative depolarization of GrCs contained within the given volume was in fact a function of spike synchrony and frequency (see Mapelli et al., 2010b). To keep into account image blurring due to light diffraction in VSD imaging recordings (Mapelli et al., 2010b), simulated images were constructed from GrCs located within $\pm 10 \mu \mathrm{m}$ from the focal plane. The spatial profile of responses to focal $\mathrm{mf}$ stimulation was constructed by computing the mean depolarization of GrCs located within spherical shells with radius between 5 and $35 \mu \mathrm{m}$ from the core of excitation. The gain of transmission of $\mathrm{mf}$ bursts was evaluated by measuring the granular layer output at a given frequency relative to the single-pulse response (Figure 7).

In order to quantify the excitatory-inhibitory balance (E-I balance), the reconstructed VSD images were analyzed as in MEA experiments. The network was stimulated to make a doublet of spikes. The intensity of excitation was measured at the peak of the first spike in control conditions. The intensity of inhibition was estimated by the changes in the second spike caused by GABA receptor blockage (see Mapelli and D’Angelo, 2007; see Figure 5).

In this work three definitions of the coefficient of variation were used for consistency with different experimental works: $\mathrm{cv}=\mathrm{SD} /$ mean, numeric $\mathrm{cv}=\mathrm{MAD} /$ median, $\mathrm{cv}_{2}=$ mean $\left[2 \times\left|\mathrm{ISI}_{n+1}-\mathrm{ISI}_{n}\right| /\right.$ $\left(\right.$ ISI $_{n+1}+$ ISI $\left._{n}\right)$ ] (Holt et al., 1996).

\section{RESULTS}

\section{RESPONSE OF SINGLE GrCs AND GoCs EMBEDDED INTO THE GRANULAR LAYER NETWORK}

Once embedded into the network, single neurons receive a continuous barrage of excitatory and inhibitory synaptic inputs driven by network-dependent activity. This can alter short-term facilitation and depression and the threshold and precision of spike firing (Dobrunz and Stevens, 1999; Klyachko and Stevens, 2006). The intrinsic responsiveness and synaptic activation of single GrCs and GoCs was assessed in model neurons embedded into the simulated granular layer network (Figures 2-4), which generated a continuous background activity (see Materials and Methods). Intrinsic responsiveness was assessed through intracellular current injection and synaptic responses were elicited by delivering a 100-Hz burst composed of five impulses over a small bundle of eight adjacent and unbranched $\mathrm{mfs}$. With this stimulus, the response occupied a surface of about $30 \mu \mathrm{m}$ diameter reflecting the spots observed with VSD recordings in slices (Mapelli et al., 2010a,b) and matching the granular layer functional units reported by Sultan and Heck (2003) (the spatial aspects of the response are considered in detail below, see Figures 5 and 6).

The GrC model (Figure 2A1) background activity comprised EPSPs generated by mfs and IPSPs generated by GoCs, while spontaneous firing was almost absent. The GrC model properly reproduced responses to current injection (Figure 2B1; D'Angelo et al., 1995, 2001). Most salient properties were non-sagging inward rectification in the subthreshold range and regular firing with almost no adaptation during depolarization, with maximum frequencies as high as $500 \mathrm{~Hz}$ (Figure 2B1). In response to a brief mf burst, the GrC model showed various responses depending on the number of active excitatory synapses and on the number and timing of IPSPs received through the $\mathrm{mf}-\mathrm{GoC}-\mathrm{GrC}$ (feed-forward) and $\mathrm{mf}-\mathrm{GrC}$ GoC-GrC (feed-back) loops (Figure 2C1). In response to a short $\mathrm{mf}$ spike burst, the GrC model generated EPSPs showing short-term depression of the transient component and temporal summation of the protracted component, which could lead to brief spike bursts. The background and evoked activity of GrCs faithfully reproduced patch-clamp recordings in vivo (Eccles et al., 1967; Chadderton et al., 2004; Jörntell and Ekerot, 2006; Rancz et al., 2007).

The GoC model (Figure 2A2) showed spontaneous activity determined by its pacemaker properties (Dieudonné, 1998; Forti et al., 2006) and modulated by $\mathrm{mf}$, pf and SC/BC synaptic inputs. The GoC maintained a firing rate of $8.4 \mathrm{~Hz}$ with $\mathrm{cv}_{2}=0.44$, consistent with recordings in vivo (Vos et al., 1999; Solinas et al., 2007b). Upon current injection (Figure 2A2), the GoC model showed the complex repertoire of dynamic rebounds observed in recordings in slices, including firing with adaptation during depolarization, sagging inward rectification during hyperpolarization, rebound excitation on return to the resting state from 


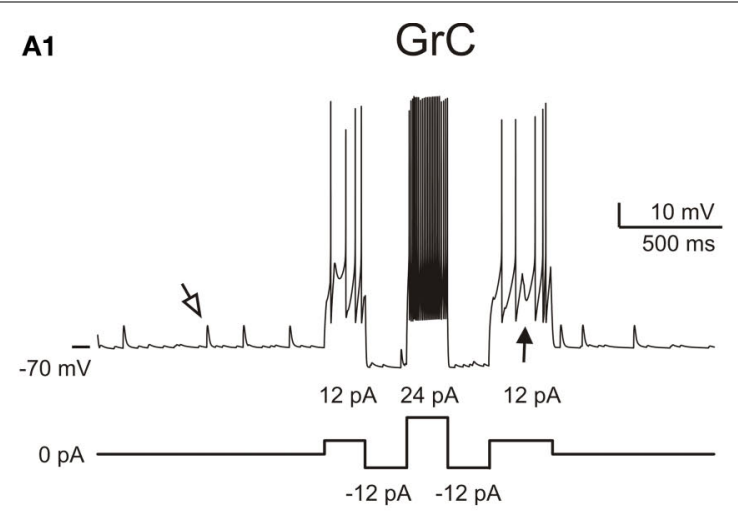

B1

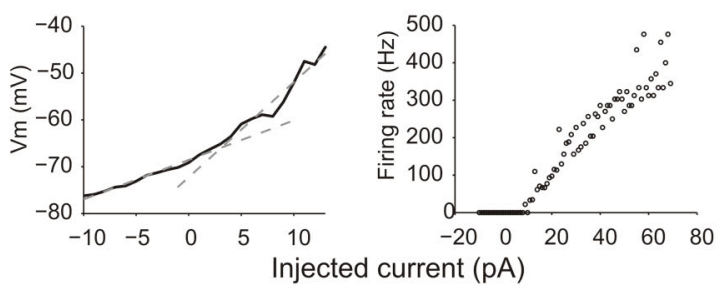

C1

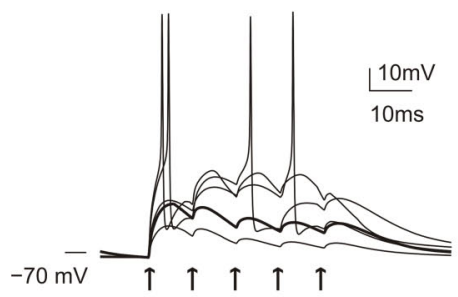

A2

GoC

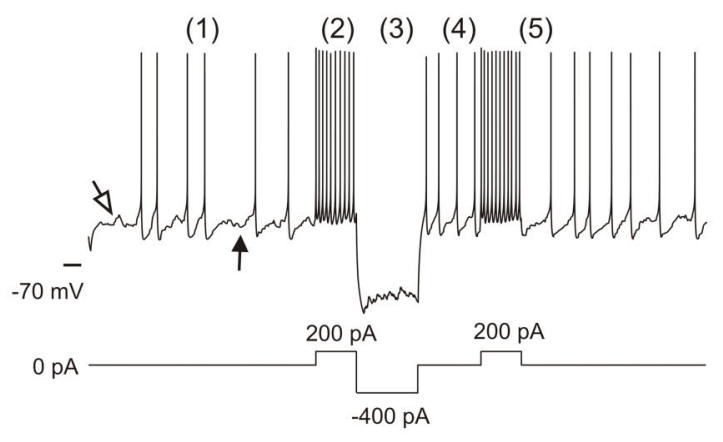

B2
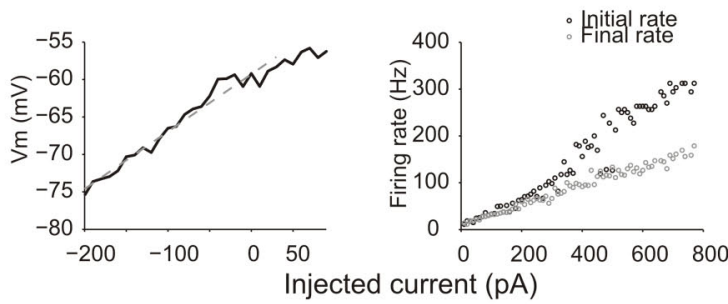

C2
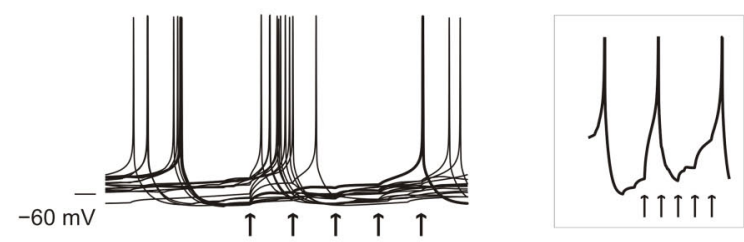

C3

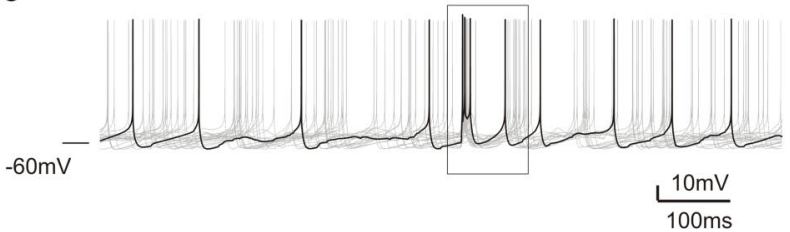

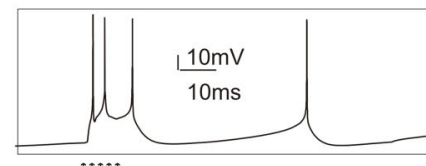

IाTाI
FIGURE 2 | Responses of GrCs and GoCs in the network. (A) The response of a $\mathrm{GrC}$ (A1) and a GoC (A2) to current injection. As in all the following simulations, the neurons are affected by background activity. The $\mathrm{GrCs}$ show EPSPs (open arrow) caused by mf activity and IPSPs (filled arrow) caused by GoC activity (the IPSPs are only visible when the neuron is depolarized, since GABA-A receptor $\mathrm{Cl}^{-}$reversal potential is almost coincident with resting potential). The GoC shows a low-amplitude synaptic noise, caused by $\mathrm{mf}$ and $\mathrm{pf}$ EPSPs (open arrow) and by SC/BC IPSPs (filled arrow), and low-frequency spiking due to intrinsic pacemaking. Both the $\mathrm{GrC}$ and the $\mathrm{GoC}$ maintain their characteristic discharge patterns previously described in slice preparations. The $\mathrm{GrC}$ shows a discharge proportional to injected current. The GoC shows (1) pacemaking, (2) spike frequency adaptation during depolarization, (3) sagging inward rectification, (4) rebound excitation following hyperpolarization, (5) phase reset after a high-frequency burst. (B) Input-output relationships for a $\mathrm{GrC}$ (B1) and a $\mathrm{GoC}$ (B2) in response to current injection. The $\mathrm{GrC}$ shows fast inward rectification (the $\mathrm{V} / \mathrm{I}$ curve is fitted with two straight lines, with slope corresponding to input resistance of $842 \mathrm{MOhm}$ and $2 \mathrm{GOhm}$, respectively). The
$\mathrm{GrC}$ shows an almost linear spike frequency increase up to $500 \mathrm{~Hz}$. The $\mathrm{GoC}$ does not show fast inward rectification (the $V / I$ curve is fitted with a single straight lines, with slope corresponding to input resistance $80 \mathrm{MOhm})$. The $\mathrm{GrC}$ shows an almost linear spike frequency increase up to $300 \mathrm{~Hz}$ and a rapid adaptation nearly halving the firing frequency. (C) The effect of an input spike burst (five spikes at $100 \mathrm{~Hz}$ on eight contiguous $\mathrm{mfs}$ ) on $\mathrm{GrCs}$ (C1) and GoCs $(\mathbf{C 2}, \mathbf{C 3})$. Examples are taken from neurons receiving a variable number of $\mathrm{mf}$ inputs. The $\mathrm{GrCs}$ (C1) receive from one to five active inputs. With weak activation EPSP short-term depression is visible (thick trace also enlarged in the inset), while with strong activation the $\mathrm{GrCs}$ emit short spike bursts. When the GoC receives eight active $\mathrm{mf}$ inputs (C2), the different traces show a single spike occurring at different phases of the pacemaking cycle followed by phase reset. Individual EPSPs are small and barely visible (thick trace also enlarged in the inset). When the $\mathrm{GoC}$ receives $45 \mathrm{mf}$ inputs ( 5 spikes at $500 \mathrm{~Hz}$ ) (C3), the traces show a short burst of two to three spikes at high frequency followed by phase-reset. The spikes in the burst (see inset) arise in $1.5 \mathrm{~ms}$ after the stimulus and then occur after 3.3, 7.6 and $47.2 \mathrm{~ms}$. 
hyperpolarization and phase-reset on return to the resting state from burst firing (Solinas et al., 2007a,b). The GoC model reached firing rates as high as $350 \mathrm{~Hz}$ (Figure 2B2). In response to a brief mf burst (Figure 2C2), the GoC model generated EPSPs determined by direct $\mathrm{mf}-\mathrm{GoC}$ activation and by propagation of activity through the mf-GrC-GoC loop (Cesana et al., 2009). With a weak input $(8 \mathrm{mfs})$ the GoC generated a single spike and phase reset the pacemaker. With a strong input ( $45 \mathrm{mfs}$ ) the GoC generated a brief burst composed of two to three spikes followed by phase reset (Figure $\mathrm{2C}_{3}$, inset) as observed following punctuate stimulation in vivo (Vos et al., 1999; Solinas et al., 2007b). The spikes were generated in $1.5 \mathrm{~ms}$ and the burst reached an initial frequency of over $300 \mathrm{~Hz}$ (cf. Kanichay and Silver, 2008). The background and evoked activity of GoCs as well as their firing patterns are in keeping with extracellular recordings in vivo (for review and other references see D'Angelo, 2008).

These simulations show that the GrC and GoC models [for GrCs: D'Angelo et al. (2001), Nieus et al. (2006), Diwakar et al., (2009); for GoCs: Solinas et al. (2007a,b)] adapted to $37^{\circ} \mathrm{C}$ and subjected to background and stimulated network activity, were able to reproduce the typical response patterns observed in vivo [for GrC: Chadderton et al. (2004), Jörntell and Ekerot (2006), Rancz et al. (2007); for GoC: Vos et al. (1999)].

\section{SUBCELLULAR MECHANISMS DETERMINE TIMING OF GrC AND GoC RESPONSES IN THE NETWORK}

While neuronal responses in slices look stereotyped, the responses of GrCs and GoCs embedded into the network show a remarkable variability. This is due to random background activity, to variations in the number and strength of synaptic contacts and to the assortment of excitatory and inhibitory fibers impinging on a given cell. Figure 3 shows the cell-specific contribution of glutamate and GABA-A receptors to dendritic responses of $\mathrm{GrCs}$ and GoCs.

Fast excitatory transmission was ensured through AMPA receptor-mediated currents, which showed short-term depression at the mf-GrC and mf-GoC synapses and short-term facilitation at the pf-GoC synapses. Slow excitation was sustained by the NMDA and the kainate receptor-mediated currents, the former being most evident at the mf-GrC synapse and the latter being specifically expressed at the pf-GoC synapse (Dieudonné, 1998; Bureau et al., 2000; Misra et al., 2000; Kanichay and Silver, 2008; Cesana et al., 2009). Thus, whereas all excitatory synapse could efficiently react to spike bursts, only the mf-GrC synapse was sensitive to fast transitions in firing rate. Inhibition was mediated by GABA-A currents both at the GoC-GrC and at the SC/BC-GoC synapses. At the GoC-GrC synapses, GABAergic currents were protracted by the slow kinetics of GABA-A $\alpha 6$ receptors (see below; D'Angelo et al., 1995; Rossi and Hamann, 1998; Mapelli et al., 2009). Therefore, potentially, the network could implement the time-window mechanism (requiring fast $\mathrm{GrC}$ responses and delayed $\mathrm{GoC}$ reaction through the $\mathrm{mf}-\mathrm{GoC}-\mathrm{GrC}$ or feed-forward inhibitory loop; D'Angelo and De Zeeuw, 2009), high pass filtering (requiring frequency-dependent build-up of the burst response through NMDA currents at the mf-GrC relay), and slow oscillations (through the pf-GoC-GrC or feed-back inhibitory loop). These properties are considered below.

\section{GLOMERULAR TRANSMISSION: POSTSYNAPTIC RECEPTOR ACTIVATION AND RELEASE PROBABILITY}

Among the processes controlling the GrC response, there are some that merit specific mention, since they are thought to confer the GrC with specific integration properties: the regulation of synaptic excitation by NMDA and GABA-A receptors and the regulation of neurotransmission by $\mathrm{mf}-\mathrm{GrC}$ release probability (Figure 4A). In addition to AMPA receptors, GrCs have the most prominent expression of NMDA receptors in the cerebellum (Cull-Candy et al., 1998) and, unique in the brain, express the $\alpha 6$ subunit of GABA-A receptors (Farrant and Nusser, 2005). Both NMDA and GABA-A $\alpha 6$ receptors have slow kinetics and are highly sensitive to neurotransmitter spillover (see also Figure 3).

In these simulations, blocking the NMDA receptors markedly reduced EPSP temporal summation delaying and curtailing the $\mathrm{GrC}$ response, while blocking GABA-A $\alpha 1$ and GABA-A $\alpha 6$ receptors sorted the opposite effect. The time of occurrence for the 1st, $2 \mathrm{nd}, 3 \mathrm{rd}, 4$ th spikes was $6.5 \pm 1.1(n=20), 14.1 \pm 1.3$ $(n=5), 24.6 \pm 1.3(n=4), 36.4 \pm 1.6(n=4) \mathrm{ms}$ in control; $5.4 \pm 0.4$ $(n=34), 16.0 \pm 2.0(n=35), 24.4 \pm 1.6(n=37), 34.5 \pm 1.9(n=21)$ ms with $\alpha 6$ receptor block; $5.3 \pm 0.5(n=36), 13.3 \pm 1.0(n=106)$, $23.6 \pm 0.8(n=34), 33.4 \pm 0.6(n=64)$ ms with $\alpha 1$ and $\alpha 6$ receptor block. Thus, both $\alpha 1$ - and $\alpha 6$-containing GABA-A receptors controlled the number and the regularity of $\mathrm{GrC}$ spike discharge.

Mf-GrC release probability can be tuned by long-term synaptic plasticity (Sola et al., 2004; D'Errico et al., 2009) and regulate the rate of short-term depression and EPSP temporal summation (Nieus et al., 2006). In the model, GrC spikes at low release probability were delayed and less numerous compared to those at high release probability (Figure 4A), confirming the experimental observations obtained during LTP and LTD recordings in slices and in vivo (Nieus et al., 2006; Roggeri et al., 2008).

Once considering the whole $\mathrm{GrC}$-GoC circuit, the relative timing of $\mathrm{GrC}$ and $\mathrm{GoC}$ activity became evident (Figure 4B). In response to an input burst, the GrCs and GoCs coactived by the same mf set fired almost at the same time (it should be noted that the reaction time of GrCs and GoCs conforms to experimental measurements: D’Angelo et al., 1995; Kanichay and Silver, 2008; Cesana et al., 2009). An additional delay was due to the time spent at the GoC-GrC synapse for GABA release and for the opening of GABA channels. This allowed the GrCs to generate a short spike burst before being inhibited.

These observations indicate that the mechanisms and reaction times of the circuit are appropriate to implement spatio-temporal filtering according to the time-window hypothesis (see also Figures 2 and 3; D'Angelo and De Zeeuw, 2009).

\section{LATERAL INHIBITION AND CENTER-SURROUND ORGANIZATION OF THE GRANULAR LAYER RESPONSE}

A main organizing principle deriving from MEA (Mapelli and D’Angelo, 2007) and VSD (Mapelli et al., 2010a,b) experiments is that activation of the $\mathrm{mf}$ bundle generates alternated areas of excitation and inhibition, which, on average, are organized in a center-surround manner. The origin of this effect has been attributed to the larger extension of the GoC inhibitory field compared to the GoC input through the basal dendrites, but a single center-surround structure was experimentally hard to 


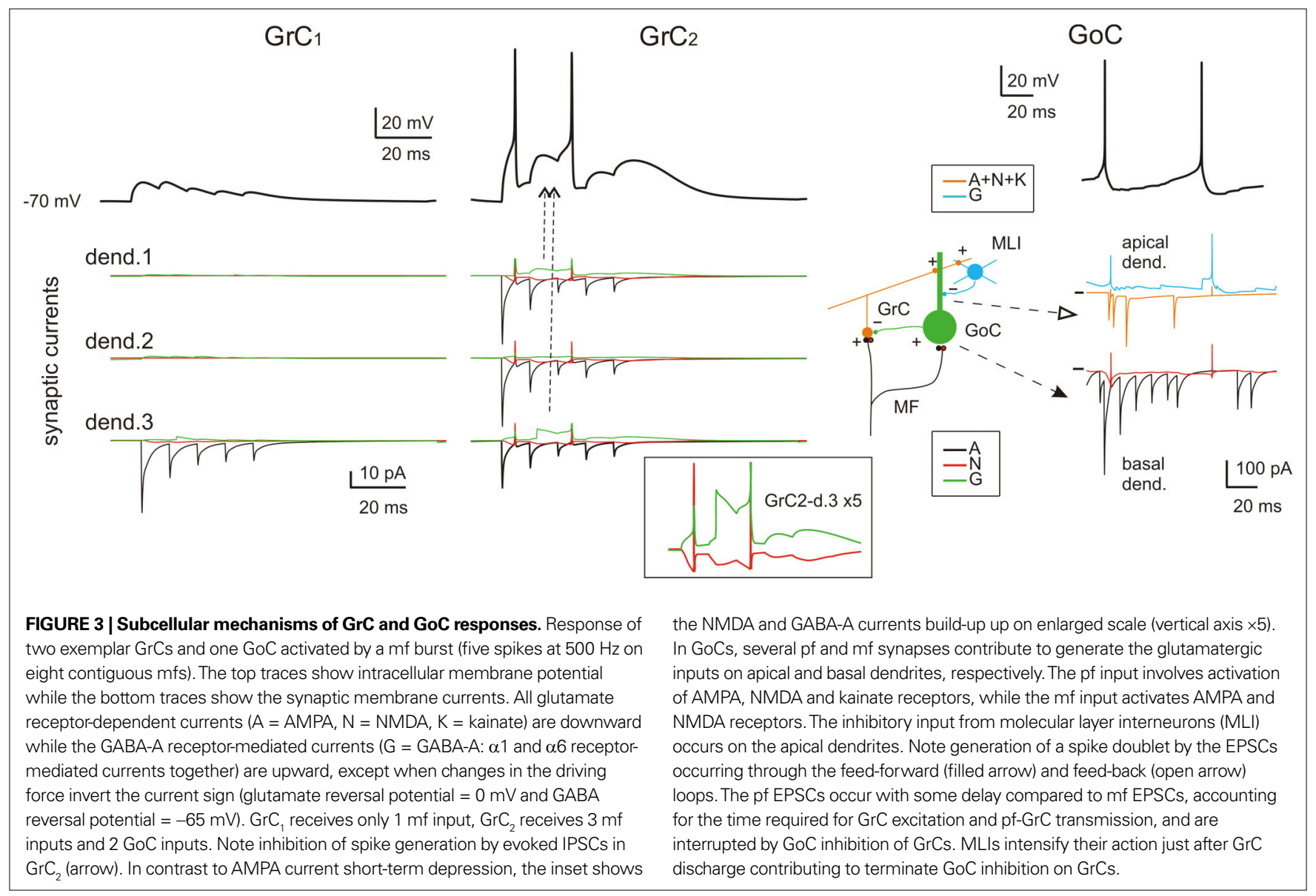

isolate. To test the center-surround hypothesis, the model was activated through eight neighboring unbranched $\mathrm{mfs}$ with 500$\mathrm{Hz}$ bursts composed of just two spikes (similar results were also obtained with longer bursts, data not shown). Mf stimulation caused a doublet of spikes forming a spot of activity that degraded around the core. Then, blocking inhibition increased the intensity and extension of the response. As explained in our previous paper (Mapelli and D'Angelo, 2007), the difference between the response before and after inhibition allowed to quantify the excitatory-inhibitory balance (E-I balance) (Figure 5A, right). The E-I balance was evaluated using the first peak to estimate excitation and the changes of the second peak caused by GABA receptor blockage to estimate inhibition (see Mapelli and D'Angelo, 2007, Materials and Methods and Figure 5B). The spatial profile of the E-I balance revealed a Mexican-hat profile indicative of centersurround organization, in which inhibition overcomes excitation around the core (Figure 5C).

\section{THE IMPACT OF CENTER-SURROUND ORGANIZATION ON SPIKE TRANSMISSION}

The center surround organization bore consequences for the way spikes were transmitted through the granular layer. In the center, where the E-I balance is higher, the depolarization was faster and the inhibitory window closed more slowly, so that the GrCs emitted spike bursts with shorter delay, higher rate and longer duration than in the surround. This effect was particularly evident by comparing the PSTH generated by two exemplar GrCs, one in the center and the other in the surround (Figure 6A).

Inhibition in the model respected two rules derived from experimental observations. Just one GoC axon was allowed to enter into a glomerulus and to form inhibitory synapses on all the GrC dendrites therein. Moreover, a GoC axon entering a glomerulus was prevented from accessing the neighboring glomeruli, which shared GrCs with the first glomerulus. This prevented a $\mathrm{GrC}$ from being inhibited twice through the same GoC (see Mapelli et al., 2009) and clustered inhibitory synapse belonging to closed $\mathrm{mf}-\mathrm{GrC}-\mathrm{GoC}-\mathrm{GrC}$ and $\mathrm{mf}-\mathrm{GoC}-\mathrm{GrC}$ loops. The extent to which the center-surround organization depended on this synaptic organization of inhibition was assessed by comparison with a mesh-like GoC-GrC connectivity merely based on statistics. In the mesh configuration, late spikes were more common and the time-window effect was less pronounced (Figure 6B). The core remained more excited after the first spike, while the surround appeared less affected (Figure 6C). Thus, time-window and the center-surround effects generated by the feed-forward inhibitory loop were enhanced by the specific topology of inhibitory connections.

These simulations suggest that the center-surround organization benefits of the specific connectivity of the inhibitory synapses and allows for a selective control of spike transfer through the core, as further considered below. 


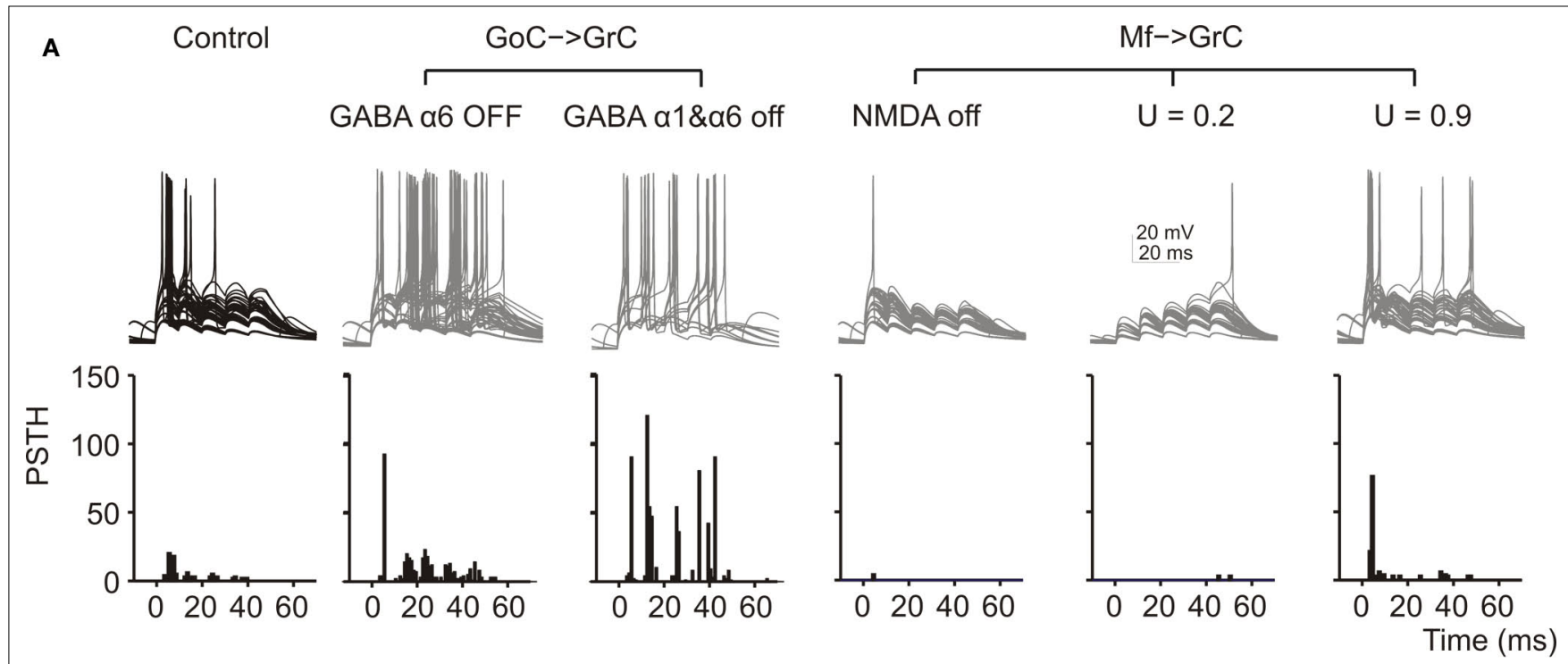

B

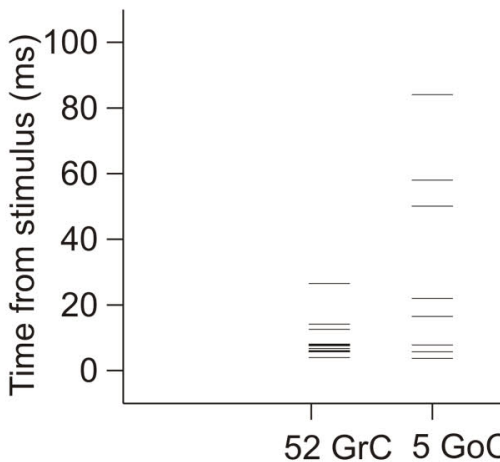

Control

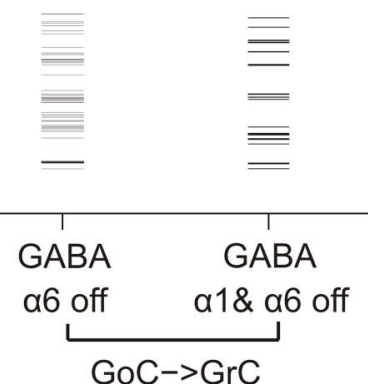

52 Granule cells

FIGURE 4 |The impact of molecular/cellular mechanisms on GrC synaptic excitation in the network. (A) Response of $\mathrm{GrCs}$ activated by a mf burst (five spikes at $100 \mathrm{~Hz}$ on eight contiguous $\mathrm{mfs}$ ). Each group of traces corresponds to the same $52 \mathrm{GrCs}$ sharing a common bursting $\mathrm{mf}$. The underlying PSTH reports the probability of spike occurrence in 1-ms bins for all (250) GrCs responding to the mf burst. Note that the switch-off of GABA-A $\alpha 6$ receptors and even more of GABA-A $\alpha 1+$ GABA-A $\alpha 6$ receptors, which control the fast and slow components of inhibition, considerably enhances spike generation protracting the duration of the output burst. Blocking the NMDA receptors prevents EPSP temporal summation reducing the $\mathrm{GrC}$ response. Decreasing release probability slows down temporal summation while increasing release probability accelerates temporal summation, with opposite effects on the rate of the $\mathrm{GrC}$ resposne. (B) The raster-plot shows the timing of individual spikes in different conditions for the same $52 \mathrm{GrCs}$ shown in (A) and for $5 \mathrm{GoC}$. Note that GoCs, through GABA-A $\alpha 1$ and $\alpha 6$ receptors, regulate the duration of the time window for $\mathrm{GrC}$ discharge, which normally lasts 5-10 ms from the stimulus. Repetitive $\mathrm{GrC}$ firing is prevented by the block of NMDA receptors and by a low release probability.

\section{FREOUENCY-DEPENDENCE OF GRANULAR LAYER TRANSMISSION AND} PREDICTIONS ON ITS REGULATION

The mfs can discharge at different frequencies (Kase et al., 1980; Van Kan et al., 1993, 1994; Arenz et al., 2008). In the model, the network was stimulated using bursts of five impulses activating eight neighboring $\mathrm{mfs}$ repeated at frequencies between 5 and $500 \mathrm{~Hz}$ (Figure 7A; see Materials and Methods). Raising stimulation frequency from 5 to $500 \mathrm{~Hz}$ increased temporal summation (Figure 7B) and spike generation in GrCs. As a consequence, the response increased following a sigmoidal gain curve with cut-off frequency around $100 \mathrm{~Hz}$ (Figure 7C). The frequency-dependent enhancement of excitation matched the high-pass filtering properties of the granular layer observed experimentally (Mapelli et al., 2010b).

The granular layer transmission properties strictly depended on specific synaptic receptors (Figure 7C). When NMDA receptors were blocked, the transmission curve was selectively depressed at low-frequency (below $20 \mathrm{~Hz}$, where EPSP temporal summation was more critically dependent on NMDA receptors; cf. D'Angelo et al., 1995) but the high-pass filtering properties were maintained. When GABA-A $\alpha 6$ receptors were blocked, the transmission curve was enhanced especially at low frequency, 


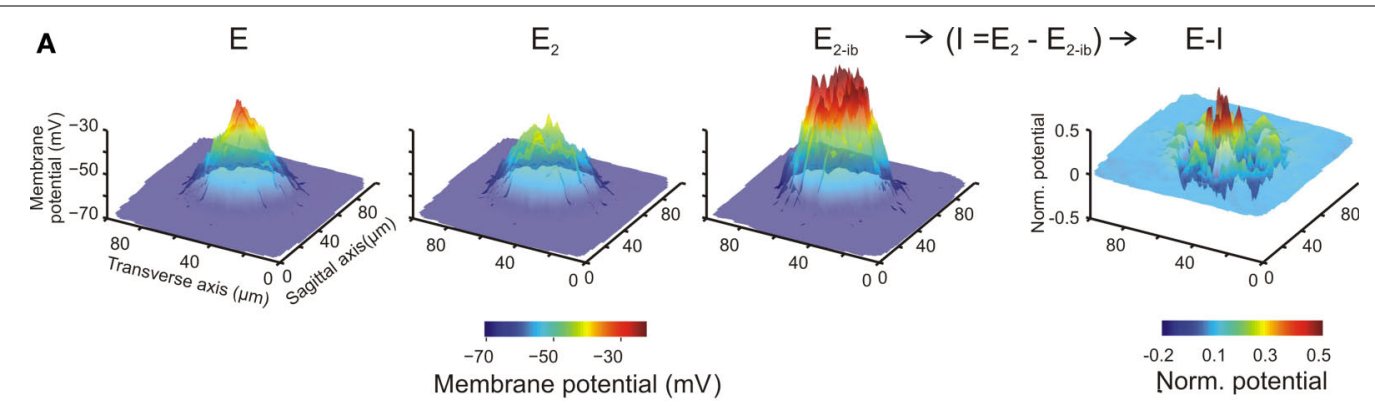

B

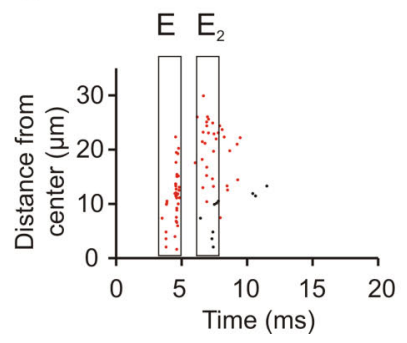

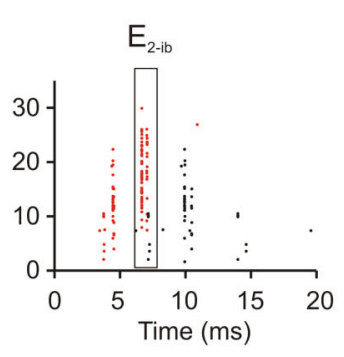

C

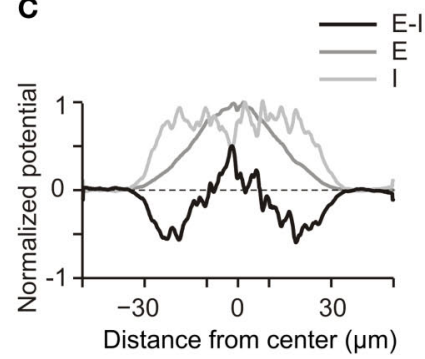

FIGURE 5 | Center surround organization and lateral inhibition. (A) Spatial pattern of $\mathrm{GrC}$ responses to a short mf burst (two spikes at $500 \mathrm{~Hz}$ on eight contiguous $\mathrm{mfs}$ ) at the time of the first spike (E) and of the second spike $\left(E_{2}\right)$. $E_{2-b i}$ indicates the response at the time of the second spike when inhibition is blocked. Since inhibition arises after excitation, it is does not affect generation of the first spike but markedly reduces generation of the second and following spikes. Thus, the influence of inhibition on the $\mathrm{GrC}$ response was obtained as ( $\mathrm{I}=\mathrm{E}-\mathrm{E}_{2-\mathrm{bi}}$. The difference between excitation and inhibition $(\mathrm{E}-\mathrm{I})$ reveals that inhibition is especially effective in reducing excitation around the core, generating a Mexican hat profile. The plots were the average of 10 simulations using different random seeds for synaptic connectivity. (B) Spikegrams for all active GrCs ordered from center to periphery [data from one of the simulation used to make $(\mathbf{A})$ ]. The first spikes are indicated by red dots, the second and following spikes by black dots. In the center the first spike occurs about $5 \mathrm{~ms}$ after the stimulus, whereas in the surround it tends to occur later. The second spike, which is quite rare in control, becomes well evident when inhibition is blocked. (C) The spatial profile of inhibition (I) was subtracted from the profile of excitation (E) to obtain the $E-I$ balance (E-I) along a section passing through the core of the corresponding plot in (A) (average data obtained from 10 simulations with different random seeds for synaptic connectivity). The larger extension of inhibition compared to excitation and the Mexican-hat profile of the E-I balance are evident. consistent with the slow time constant of these receptors. When both GABA-A $\alpha 6$ and GABA-A $\alpha 1$ receptors were blocked the transmission curve was enhanced at all frequencies and highpass filtering was strongly reduced. These results, which are in keeping with experimental observations obtained with VSD imaging (Mapelli et al., 2010b), indicate that the high-pass filtering properties of granular layer depend on phasic GABAA receptor-dependent transmission (no further changes were obtained by blocking the tonic GABA-A receptor-mediated current, not shown).

The granular layer transmission properties also depended on glutamate release probability at the $\mathrm{mf}-\mathrm{GrC}$ synapse (Figure 7C). Reducing release probability from the control value 0.6 to 0.2 depressed temporal summation yielding an effect similar to blocking NMDA receptors. Raising release probability to 0.9 enhanced transmission at low-frequency but not at high-frequency (probably because EPSP short-term depression became so strong that temporal summation was prevented).

The frequency dependence of the granular layer response changed moving from the center to the surround of the responding area (Figure 7D). In the center, the high-pass filtering curve arose at lower frequencies and attained a higher maximum gain than in the surround. Moreover, the gain difference between center and surround was more pronounced at high than low input frequency (the ratio between gain measured at 10 and $25 \mu \mathrm{m}$ from the core was 3 at $300 \mathrm{~Hz}, 2.3$ at $100 \mathrm{~Hz}$ and 1.5 at $50 \mathrm{~Hz}$; Figure 7E). Thus, the center-surround is predicted to generate complex transformations of incoming mf signals.

\section{THE EMERGENCE OF OSCILLATION AND PREDICTIONS ON THEIR REGULATION}

In vivo, GrCs show rare spontaneous activity (Chadderton et al., 2004; Jörntell and Ekerot, 2006; Rancz et al., 2007). However, in certain circumstances, the ensemble activity generated by the granular layer can take the form of coherent oscillations $[7 \mathrm{~Hz}$ in the rat (Hartmann and Bower, 1998) and 7-25 Hz in the monkey (Pellerin and Lamarre, 1997; Courtemanche et al., 2009)]. It was not clear if this sparse GrC background activity could sustain the coherent oscillations.

In these simulations, the model was driven by random mf activity at different frequencies (see Materials and Methods) generating a sparse low-frequency discharge of $\mathrm{GrCs}(<1 \mathrm{~Hz} /$ cell; Figure 8A) reflecting the basal GrC activity recorded in the anesthetized rat (Chadderton et al., 2004; Rancz et al., 2007) and in the decerebrated cat (Jörntell and Ekerot, 2006). When basal mf activity was low $(10 \mathrm{~Hz})$ ensemble activity was barely detectable but when basal mf activity was higher $(20-40 \mathrm{~Hz})$ the granular layer generated coherent oscillations at 7-15 Hz. Coherent oscillations were never easily resolved in single GrCs, which maintained a sparse activity, but clearly emerged as a population activity in the spikegrams. 


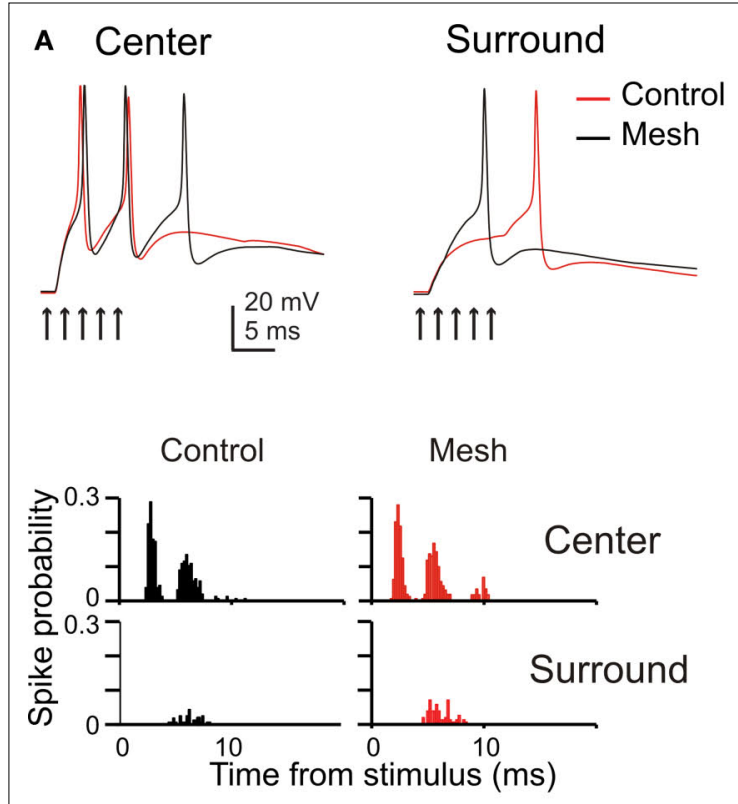

FIGURE 6 |The impact of network topology on granular layer responses. Granular layer response elicited by a mf burst (five spikes at $500 \mathrm{~Hz}$ on eight contiguous $\mathrm{mfs}$ ) using the control or the mesh-like network configurations (see Materials and Methods). (A) The traces show that responses in the center have shorter latency and higher number of spikes than in the surround of the activated area (exemplar traces are taken at 10 and $32 \mu \mathrm{m}$ from the core; arrows mark the time of stimulation). The PSTHs (bin width $0.5 \mathrm{~ms}$ ) were normalized by the number of simulations. The mesh-like configuration reduces the overall level of inhibition, with a more evident effect in the surround, so that the PSTH of peripheral cells shows a remarkable increase in the second/third spike firing probability. (B) The PSTHs of responding $\mathrm{GrCs}$ were ordered according to $\mathrm{GrC}$ distance from the stimulus center and color coded. In the control network configuration, most neurons fire a high frequency spike doublet with short
B

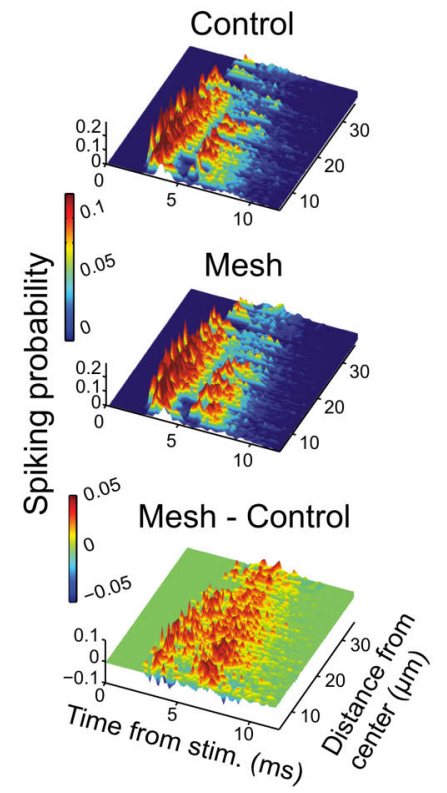

C

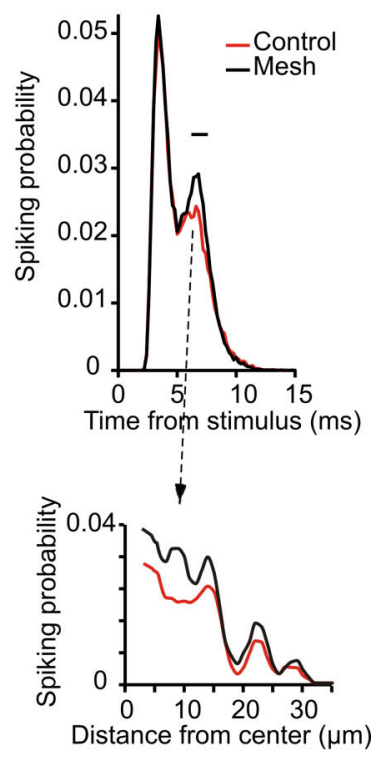

latency which, in some cases, is followed by a late spike with lower time precision. Some neurons in the periphery fire just a single late spike. The mesh network configuration shows differences in the timing of the first and second spikes and an enhanced probability of third spikes. The mesh-control plot shows sharp peaks in the early response phase due to differences in spike timing and wider peaks in the late response phase due to increase firing probability. (C) Time and space response profiles with control and mesh network

configurations. The upper plot shows the mean response of all $\mathrm{GrCs}$. The two curves show a significant difference at the time of the second spike. The point of maximum difference is at $7.2 \mathrm{~ms}$ after the stimulus and the difference is significant in the range indicated by the black bar ( $p<0.007, t$-test). The lower plot illustrates the spatial profile of control and mesh responses at the time of their maximal difference.

A measure of rhythmicity was provided by the autocorrelograms of groups of GrCs and GoCs, which showed firing at regular periods over hundreds of milliseconds. The cross-correlograms between GrCs and GoCs cells (Figure 8B) also showed coherent oscillations, indicating that activity in the two cell populations were correlated. The coherent granular layer oscillations followed those of GoCs with a 5- to 10-ms lag due to the time spent in the feed-back inhibitory loop.

The granular layer oscillation assumed a frequency correlated with that in the $\mathrm{mf}$ input, as revealed by power spectrum analysis (Figure 8C). The output frequency was typically in the $7-15 \mathrm{~Hz}$ range remaining lower than the input frequency. The oscillation was regulated by several synaptic mechanisms operating in the cerebellar glomerulus (Figure 8Di; cf. Figure 4). Blocking GrC NMDA receptors strongly reduced the PSD peak amplitude, while blocking GrC GABA-A $\alpha 6$ receptors markedly increased the PSD peak amplitude, reflecting opposite regulation on the feed-back ( $\mathrm{GrC}-\mathrm{GoC}-\mathrm{GrC}$ ) loop. Blocking both GrC GABA-A $\alpha 6$ and GABA-A $\alpha 1$ interrupted the feed-back loop and flattened the PSD curve. Another remarkable effect was generated by altering $\mathrm{mf}-\mathrm{GrC}$ release probability and therefore EPSP temporal summation. Decreasing mf-GrC release probability $(p=0.2)$ reduced the PSD peak amplitude, while increasing $\mathrm{mf}-\mathrm{GrC}$ release probability $(p=0.9)$ increased the PSD peak amplitude, again reflecting opposite regulation on the feedback loop. Moreover, (Figure 8Dii), when the feed-back loop was enhanced (GABA-A $\alpha 6$ receptor block or $p=0.9$ ) the PSD peak frequency was increased, while the opposite occurred when the loop was weakened. Therefore, synaptic mechanisms allowed to fine-tune the intensity and frequency of oscillations.

It should be noted that increasing the strength of the mf-GoC synapse (Figure 8Ei) and of the SC/BC-GoC synapse (Figure 8Eii) progressively reduced the PSD of oscillations. Thus, oscillations were critically dependent on circuit components that controlled the feed-back inhibitory loop.

\section{DISCUSSION}

This computational investigation provides a formal demonstration that available knowledge on cellular properties and circuit connectivity can explain center-surround and time-window effects during burst transmission and that sparse $\mathrm{GrC}$ random activity can sustain coherent low-frequency oscillations (D'Angelo and De Zeeuw, 2009; D'Angelo et al., 2009). The model predicts differential transmission through the center-surround structure reflecting the balance between NMDA and GABA-A receptor activation. 


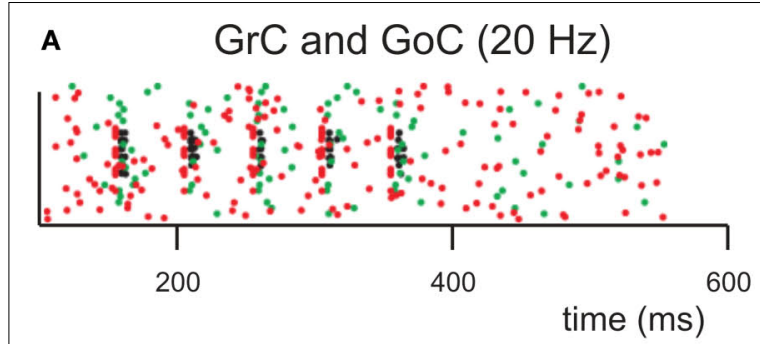

B

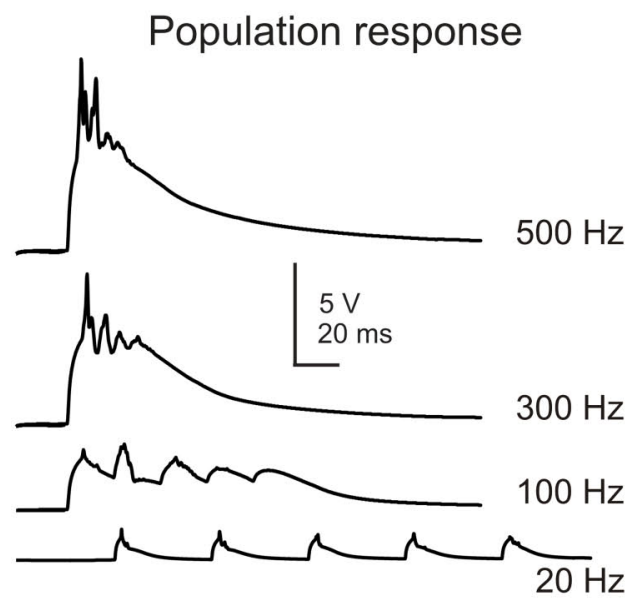

C

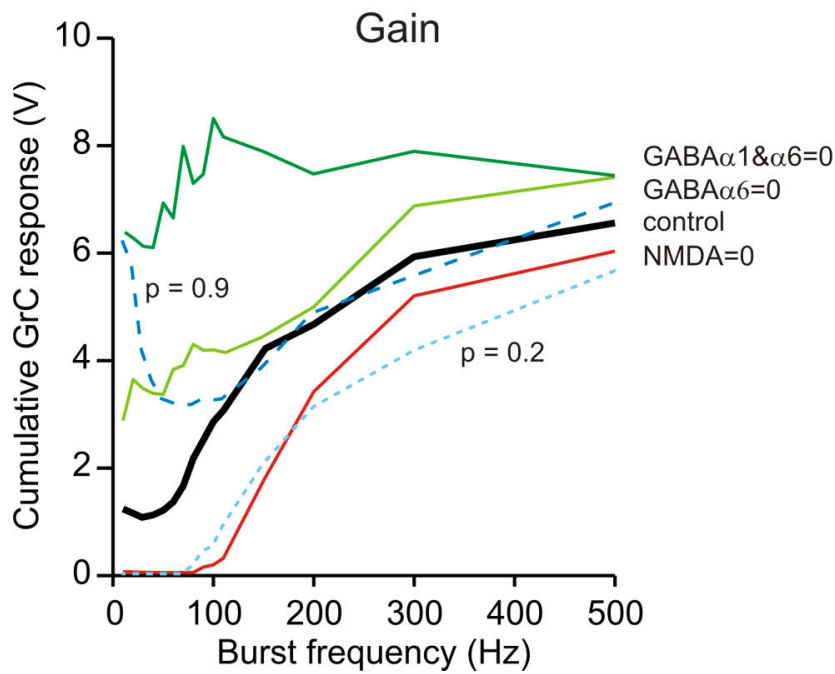

FIGURE 7| Frequency-dependence of granular layer responses. (A)The raster plot shows the response of all $\mathrm{GrCs}$ (blue dots) and GoCs (green dots) to a bursts (five spikes at $20 \mathrm{~Hz}$ ) on eight contiguous mfs (red dots). (B) The $\mathrm{GrC}$ membrane potential (traces are the sum over all active $\mathrm{GrCs}$ ) shows poor temporal summation at low stimulation frequency $(20 \mathrm{~Hz})$ but marked temporal summation at high frequencies $(>100 \mathrm{~Hz})$. (C) The gain function showed a steep increase above $50 \mathrm{~Hz}$. By blocking the NMDA receptors, the responses were depressed with a specific loss of transmission at low frequency. By blocking GABA receptors, the responses were enhanced with a more marked increase of transmission at low frequency. Reducing release probability $(p=0.2)$ depressed the gain curve at
D

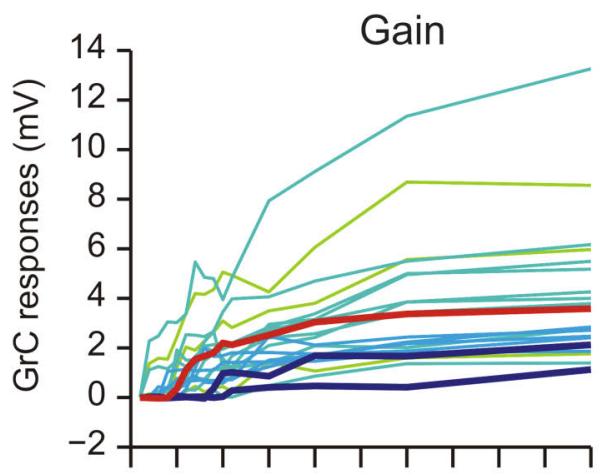

25

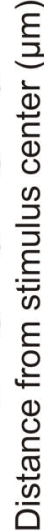

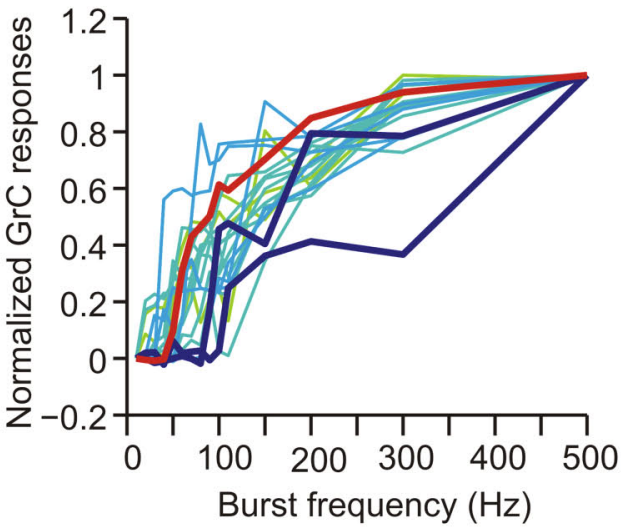

E

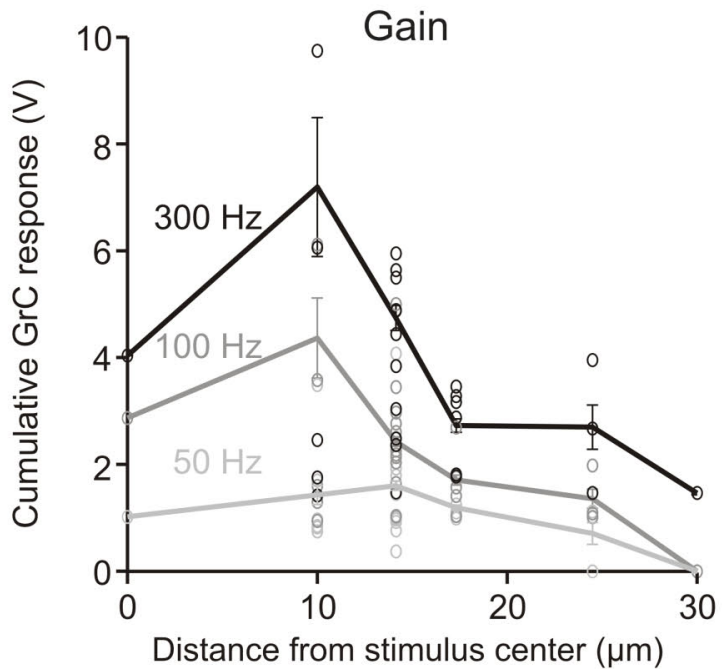

all frequencies, while raising release probability $(p=0.9)$ enhanced the gain curve specifically at low frequency. (D) The gain curve changed from the center to surround of the excited area. In the center the gain curve arose at lower frequencies and attained higher gain than in the surround. (i) shows absolute gain curves, (ii) shows normalized gain curves. Each gain trace is from a different $\mathrm{GrC}$. (E) Gain as a function of distance from the center of the active areas. The points are measures in responding spots located along different radii (mean \pm sd indicate the values along the whole circumference at the given distance; see Materials and Methods for details). The difference between center and surround in terms of gain was more pronounced at high than low input frequency. 

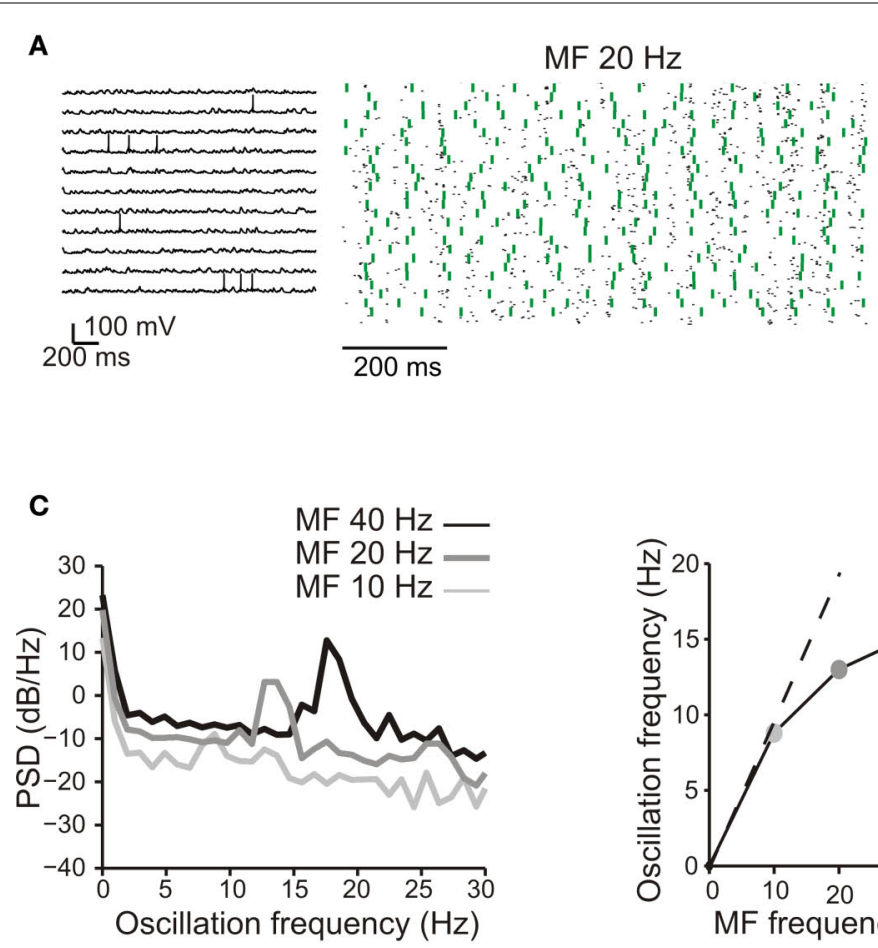

D

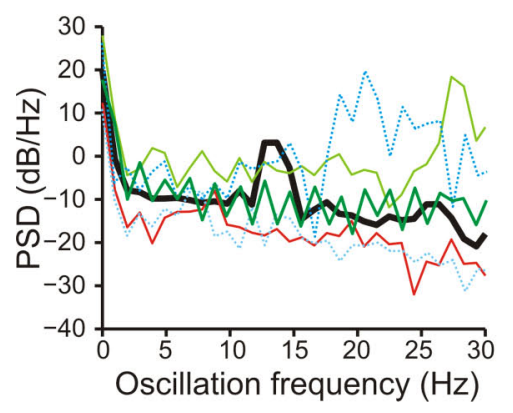

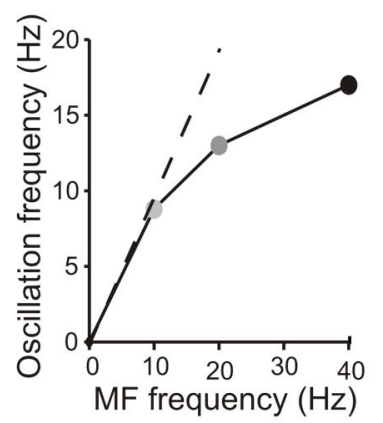

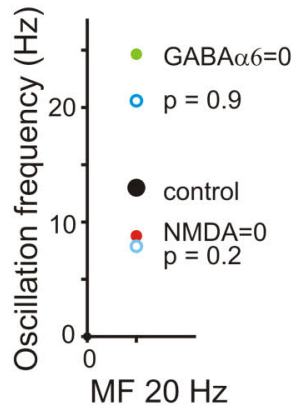

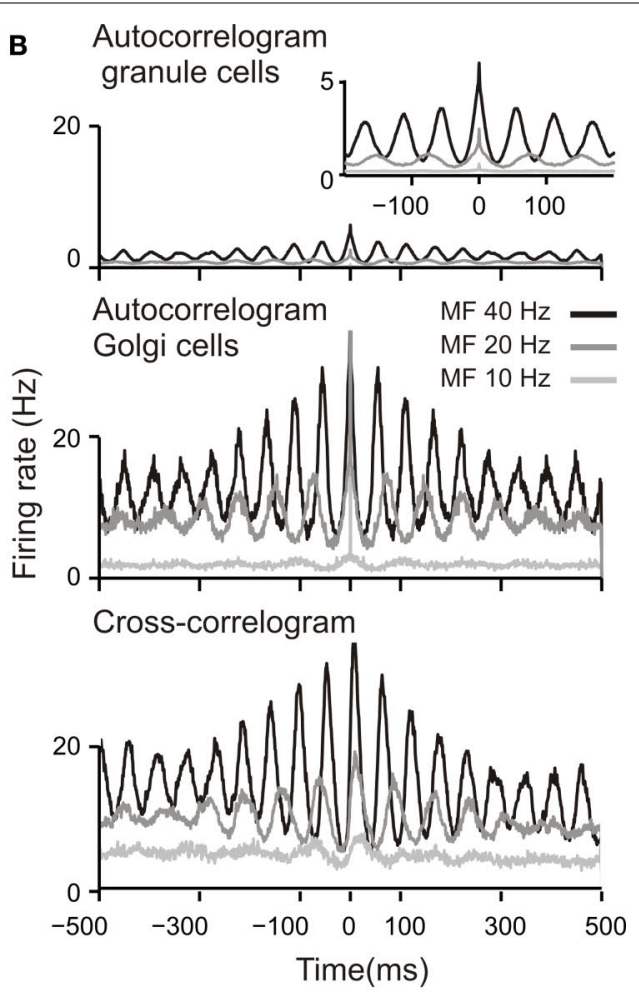

E

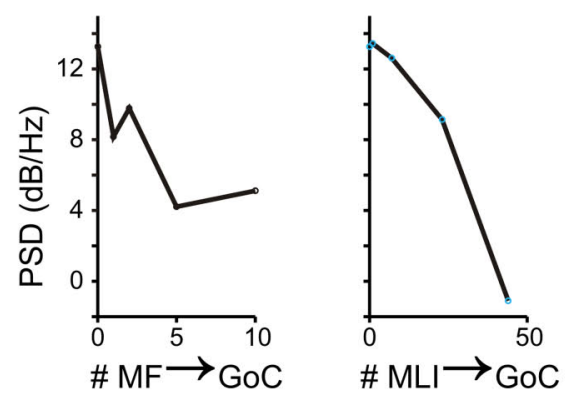

FIGURE 8 | Background activity and oscillations. (A) The response of $\mathrm{GrCs}$ and $\mathrm{GoCs}$ to a $20-\mathrm{Hz} \mathrm{mf}$ random activity. Activity of individual $\mathrm{GrCs}$ was sparse and appeared to occur at random and uncorrelated times [membrane potential traces, (i)]. However, when represented in a raster plot (ii), GrC (blue dots) and GoC (green dots) activity appeared organized in a repetitive coherent pattern. (B) Autocorrelograms of $\mathrm{GrC}$ and $\mathrm{GoC}$ population activity at three different frequencies of the random input $(10 \mathrm{~Hz}, 20 \mathrm{~Hz}, 40 \mathrm{~Hz}$; $(\mathbf{i}, \mathbf{i i})$ ). The autocorrelogram of $\mathrm{GrCs}$ is enlarged in the inset. The cross-correlogram shows the mean activity of the GoCs in relation to spikes fired by GrCs (iii). (C) The power spectrum density (PSD) of the $\mathrm{GrC}$ population activity shows a peak between 7 and $20 \mathrm{~Hz}$ at the three different input frequencies [(i): $10 \mathrm{~Hz}$, $20 \mathrm{~Hz}, 40 \mathrm{~Hz}$ ]. These peaks are represented as a function of the input frequency in (ii). (D) The effect of altering neurotransmission mechanisms on the $\mathrm{GrC}$ power spectral density generated with a $20-\mathrm{Hz}$ mf random activity. Blocking NMDA receptors reduced the PSD peak frequency, while blocking GABA-A receptors increased the PSD peak frequency. Decreasing $\mathrm{mf}-\mathrm{GrC}$ release probability $(p=0.2$ ) reduced the PSD peak frequency, while increasing $\mathrm{mf}-\mathrm{GrC}$ release probability $(p=0.9)$ increased the PSD peak frequency. (E) The effect of altering the strength of GoC excitation through the $\mathrm{mfs}$ and of $\mathrm{GoC}$ inhibition through $\mathrm{MLI}$ on the $\mathrm{GrC}$ power spectral density generated with a $20-\mathrm{Hz} \mathrm{mf}$ random activity. The oscillatory effect, revealed by the intensity of the GrC PSD, tends to vanish as the intensity of the feedforward inhibitory loop is increased and as the intensity of the feed-back disinhibitory loop is increased.
The center had a lower cut-off for input signals and generated spike bursts at higher frequency and with shorter delay than the surround. In the center the time-window closed less effectively and contained more spikes than in the surround. The higher mf$\mathrm{GrC}$ release probability in the center than in the surround due to long-term synaptic plasticity (Mapelli and D'Angelo, 2007) would further enhance the contrast between adjacent network areas. The main prediction of the model is therefore that the granular layer circuit behaves as a spatio-temporal filter, whose local properties can be adapted through long-term plasticity and different areas can be synchronized through low-frequency oscillations. It can be envisioned that distributed inputs generate a continuum 
of center-surround structures performing a complex time- and frequency-dependent transformation of input signals (e.g. Mapelli et al., 2010a) to be relayed to Purkinje cells. These results support the concept that input mossy fiber bursts are first separated and transformed in granular layer sub-circuits and then relayed to Purkinje cells for subsequent integration and pattern recognition (Dean et al., 2010).

The major innovation in this model is that membrane mechanisms are reproduced using Hodgkin-Huxley gating schemes and synaptic transmission using synaptic vesicle cycling schemes, which are based on extended electrophysiological experiments and biophysical analysis in slices (D'Angelo et al., 2001; Nieus et al., 2006; Solinas et al., 2007a,b; Diwakar et al., 2009 and references therein). Moreover, circuit structure is reproduced beyond statistical connectivity, accounting for a sophisticated arrangement of neuronal and synaptic elements (see Mapelli and D'Angelo, 2007; D'Angelo, 2008; D’Angelo and De Zeeuw, 2009; D’Angelo et al., 2009; Mapelli et al., 2009, 2010a). Finally, the simulations accounted for granular layer responses to three major $\mathrm{mf}$ discharge patterns inspired by in vivo recordings: localized bursting, frequency-modulated activity and diffused random activity (Kase et al., 1980; Chadderton et al., 2004; Jörntell and Ekerot, 2006; Rancz et al., 2007). In response to single input bursts, the model showed center-surround responses and time windowing (D'Angelo and De Zeeuw, 2009). In response to input trains at different frequencies, the granular layer behaved as a high-pass filter with a rapid growth of the response between 50 and $100 \mathrm{~Hz}$, as observed in VSD recordings (Mapelli et al., 2010b). In response to continuous random stimuli, the model generated synchronous oscillations in the theta band (Pellerin and Lamarre, 1997; Hartmann and Bower, 1998; Maex and De Schutter, 1998; Courtemanche et al., 2009).

The model, by being reconstructed from a detailed description of its constitutive elements, could account for the multiple dynamics of granular layer activity observed in vitro and in vivo. The individual GrCs and GoCs showed responses to $\mathrm{mf}$ burst stimulation compatible with those elicited in vivo following punctuate stimulation of the whisker pad (Vos et al., 1999; Chadderton et al., 2004; Rancz et al., 2007) or following more prolonged touching on the limbs (Jörntell and Ekerot, 2006). The specific firing patterns depended on the blend of local excitation and inhibition. Moreover, the neurons, although individually maintaining a low and irregular firing rate, could be entrained into coherent oscillatory activity. Therefore, the model, in addition to demonstrate that biophysical properties in vitro are sufficient to reproduce multiple activity patterns in vivo, provides the basis for investigating the contribution of single neurons to network activity and, conversely, network's influence on single neurons (Buzsáki, 2006; Izhikevich and Edelman, 2008).

Previous models [originally the theoretical models of Marr (1969), Albus (1971), Tyrrell and Willshaw (1992), Dean et al. (2010) but also the computational model of Maex and De Schutter (1998), Medina and Mauk (2000)] were based on the statistical properties of the granular layer connectivity. Here we have faced the problem of how GoCs contact GrCs in the glomeruli by using the following rules: a GoC inhibits all the dendrites in a glomerulus and cannot inhibit a GrC more than once. As a corollary, each GrC is inhibited by different (up to 5 with a mean of 4) GoCs and all GrCs sending their dendrites in the same glomerulus have at least one GoC in common. This organization, by increasing the efficiency of feed-forward loops and concentrating inhibition into certain cell subgroups, enhanced center-surround transmission and time windowing. These rules are compatible with original Golgi staining images (Golgi, 1883; Ramón y Cajal, 1887, 1889, 1904; Eccles et al., 1967; Palay and Chan-Palay, 1974) but would require further refinement of the glomerular representation in the model to improve generation of direct and indirect GABAergic responses (Rossi and Hamann, 1998; Mapelli et al., 2009) and to implement glomerular crosstalk (Mitchell and Silver, 2000a,b). It should also be noted that network topologies were not fully resolved in the model, because $\mathrm{mf}$ and GoC axon branching on the sagittal plane and pf long-range connections on the transverse plane could not be implemented on the scale of this network (see Wu et al., 1999; Sultan, 2001; Barmack and Yakhnitsa, 2008; D'Angelo, 2008).

The model identified different roles for the main components of inhibition. Lateral inhibition was critical to determine the centersurround effect, feed-forward inhibition to determine the timewindowing effect and feed-back inhibition to determine coherent oscillations. In fact, in the model, the generation of oscillatory activity in response to random $\mathrm{mf}$ bursts decreased with the strength of the feed-forward loop, which, in turn, was essential to generate time-windowing in response to localized $\mathrm{mf}$ activity. Since the relative strength of the feed-forward and feed-back loops is unknown, different mechanism can be envisaged: (i) the relative strength of feed-back and feed-forward loops is dynamically balanced through the intervention of SC/BC-GoC inhibition (Dumoulin et al., 2001) or through glomerular mechanisms (Mitchell and Silver, 2000a,b, 2003; Mapelli et al., 2009); (ii) the feed-forward loop is independently regulated through pfs originating from GrCs located outside the active beam; (iii) oscillating activity is conveyed into the cerebellum in pre-organized patterns. Although these mechanisms may coexist, the latter is especially interesting since both GrCs and GoCs have resonant properties in the theta-band (D'Angelo et al., 2001; Solinas et al., 2007a,b; D'Angelo and De Zeeuw, 2009). It is therefore possible that theta patterns at the input (around $7 \mathrm{~Hz}$ in rodents; Hartmann and Bower, 1998) are particularly efficient in generating granular layer responses (Ros et al., 2009).

The model appropriately reproduced the high-pass filtering properties of the granular layer, so that burst patterns over $50 \mathrm{~Hz}$ were efficiently transmitted while those at lower frequencies were not (Mapelli et al., 2010b). This is in keeping with the proposal that GrCs receive and retransmit high-frequency bursts (Chadderton et al., 2004; Rancz et al., 2007). The higher cut-off observed in the surround than in the center suggests that a frequency-code is spatially implemented through the center-surround structure. The gain control mechanisms based on stochastic resonance (Mitchell and Silver, 2003) may overlay with those considered here and account for the frequency-dependent modulation of incoming signals observed in certain functional conditions (Arenz et al., 2008).

In the model, generation of appropriate spatio-temporal patterns of activity of the cerebellum granular layer required a detailed description of cellular and synaptic properties. The time course of vesicle cycling regulated temporal summation during repetitive neurotransmission (see Figures 2 and 4 ) and filtering at the $\mathrm{mf}-\mathrm{GrC}$ relay (see Figure 7). Transmission at low frequency was 
enhanced by the slow time constant of excitation introduced by the NMDA receptors and was reduced by the slow time constant of inhibition introduced by GABA-A $\alpha-6$ receptors (see Figure 7), suggesting that the balance of the two is critical to regulate circuit functioning. These same mechanisms also helped maintaining network oscillations in the theta-frequency band (see Figure 8; D'Angelo et al., 2001; Solinas et al., 2007b). It should be noted that, with unconstrained parameterization, a previous model generated $40 \mathrm{~Hz}$ oscillations, which are probably non-physiological (Maex and De Schutter, 1998).

In order to assess the hypothesis that the granular layer behaves as an adaptable spatio-temporal filter coordinated by low-frequency oscillations, experimental tests may be combined with further computational investigations. First, the implementation of rules for long-term synaptic plasticity in the model of the $\mathrm{mf}-\mathrm{GrC}$ synapse (D'Errico et al., 2009) could allow investigating the impact of adaptation on network filtering and pattern recognition. Secondly, the ability of the circuit of generating theta-frequency oscillations in response to repetitive bursting (which would be naturally conveyed by the cerebral cortex; Ros et al., 2009) could be investi-

\section{REFERENCES}

Albus, J. S. (1971). A theory of cerebellar function. Math. Biosci. 10, 25-61.

Arenz, A., Silver, R. A., Schaefer, A. T., and Margrie, T. W. (2008). The contribution of single synapses to sensory representation in vivo. Science 321, 977-980.

Arleo, A., Nieus, T., Bezzi, M., Derrico, A., D’Angelo, E., and Coenen, S. O. (2010). How synaptic release probability shapes neuronal transmission: information theoretic analysis in a cerebellar granule cell. Neural Comp. 22, 1113-1148.

Armstrong, D. M., and Rawson, J. A. (1969). Activity patterns of cerebellar cortical neurones and climbing fibre afferents in the awake cat. J. Physiol. (Lond.) 289, 425-448.

Barmack, N. H., and Yakhnitsa, V. (2008). Functions of interneurons in mouse cerebellum. J. Neurosci. 28, 1140-1152.

Bureau, I., Dieudonné, S., Coussen, F., and Mulle, C. (2000). Kainate receptor-mediated synaptic currents in cerebellar Golgi cells are not shaped by diffusion of glutamate. Proc. Natl. Acad. Sci. U.S.A. 97, 6838-6843.

Buzsáki, G. (2006). Rhythms of the Brain. New York: Oxford University Press.

Cesana, E., Dieudonné, S., Isope, P., Bidoret, C., D'Angelo, E., and Forti, L. (2009). Excitatory inputs to cerebellar Golgi cells in the cerebellum. SfN Abstract 367.17.

Chadderton, P., Margrie, T. W., and Häusser, M. (2004). Integration of quanta in cerebellar granule cells during sensory processing. Nature 428, 856-860.
Courtemanche, R., Chabaud, P, and Lamarre, Y. (2009). Synchronization in primate cerebellar granule cell layer local field potentials: basic anisotropy and dynamic changes during active expectancy. Front. Cell. Neurosci. 3:6. doi: 10.3389/neuro.03.006.2009.

Cull-Candy, S. G., Brickley, S. G., Misra, C., Feldmeyer, D., Momiyama, A., and Farrant, M. (1998). NMDA receptor diversity in the cerebellum: identification of subunits contributing to functional receptors. Neuropharmacology 37, 1369-1380.

D’Angelo, E. (2008). The critical role of Golgi cells in regulating spatiotemporal integration and plasticity at the cerebellum input stage. Front. Neurosci. 2:1, 35-46. doi: 10.3389/neuro.01.008.2008.

D’Angelo, E., De Filippi, G., Rossi, P., and Taglietti, V.(1995). Synaptic excitation of individual rat cerebellar granule cells in situ: evidence for the role of NMDA receptors. J. Physiol. (Lond.) 484, 397-413.

D’Angelo, E., and De Zeeuw, C. I. (2009). Timing and plasticity in the cerebellum: focus on the granular layer. Trends Neurosci. 32, 30-40.

D’Angelo, E., Koekkoek, S. K. E., Lombardo, P., Solinas, S., Ros, E., Garrido, J., Schonewille, M., and De Zeeuw, C. I. (2009). Timing in the cerebellum: oscillations and resonance in the granular layer. Neuroscience 162, 805-815.

D’Angelo, E., Nieus, T., Maffei,A.,Armano, S., Rossi, P., Taglietti, V., Fontana, A., and Naldi, G. (2001). Theta-frequency bursting and resonance in cerebellar granule cells: experimental evidence

gated by modulating the resonant properties of GrCs and GoCs models (D’Angelo et al., 2001; Solinas et al., 2007b). Thirdly, the observation that tonic inhibition can control granular layer gain (Mitchell and Silver, 2003) could be assessed by introducing quantal mechanisms of neurotransmitter release in the model of the mfGrC synapse (Arleo et al., 2010). The integration of the current model into larger modules including the molecular layer and deep cerebellar nuclei will eventually provide a tool for investigating the spatio-temporal filtering hypothesis of the entire cerebellar network (Dean et al., 2010).

\section{ACKNOWLEDGMENTS}

This work was supported by projects SENSOPAC (FP6-IST 028056) and CYBERRAT (Bio-ICT convergence 216528) of the European Commission and by NEUROIMAGE of CNISM (Consorzio Interuniversitario per le Scienze Fisiche della Materia) to E.D. The computational facility for the most intensive simulations was provided by the parallel cluster CASPUR (Consorzio Interuniversitario per le Applicazioni di Supercalcolo per Università e Ricerca). We thank Dr. S. Masoli for his contribution to parallelization of the model.

and modeling of a slow $\mathrm{K}^{+}$-dependent mechanism. J. Neurosci. 21, 759-770.

D’Errico, A., Prestori, F., and D’Angelo, E. (2009). Differential induction of bidirectional long-term changes in neurotransmitter release by frequency-coded patterns at the cerebellar input. J. Physiol. (Lond.) 587, 5843-5857.

Dean, P., Porrill, J., Ekerot, C.-F., and Jörntell, H. (2010). The cerebellar microcircuit as anadaptive filter: experimental and computational evidence. Nat. Neurosci. Rev. 11, 30-43.

Dieudonné, S. (1998). Submillisecond kinetics and low efficacy of parallel fibre-Golgi cell synaptic currents in the rat cerebellum. J. Physiol. (Lond.) 510, 845-866.

Diwakar, S., Magistretti, J., Goldfarb, M. Naldi, G., and D'Angelo, E. (2009). Axonal $\mathrm{Na}+$ channels ensure fast spike activation and back-propagation in cerebellar granule cells. $J$. Neurophysiol. 101, 519-532.

Dobrunz, L. E., and Stevens, C. F. (1999). Response of hippocampal synapses to natural stimulation patterns. Neuron 22, 157-166.

Druckmann, S., Banitt, Y., Gidon, A. Schürmann, F., Markram, H., and Segev, I. (2007). A novel multiple objective optimization framework for constraining conductance-based neuron models by experimental data. Front. Neurosci. 1:1, 7-18. doi: 10.3389/neuro.01.1.1.001.2007.

Dumoulin, A., Triller, A., and Dieudonné, S. (2001). IPSC kinetics at identified GABAergic and mixed GABAergic and glycinergic synapses onto cerebellar Golgi cells. J. Neurosci. 21, 6045-6057.

Eccles, J. C., Ito, M., and Szentagothai, J. (1967). The Cerebellum as a Neuronal Machine. Berlin: Springer.

Farrant, M., and Nusser, Z. (2005). Variations on an inhibitory theme: phasic and tonic activation of GABAA receptors. Nat. Rev. Neurosci. 6, 215-229.

Forti, L., Cesana, E., Mapelli, J., and D’Angelo, E. (2006). Ionic mechanisms of autorhythmic firing in rat cerebellar Golgi cells. J. Physiol. (Lond.) 574, 711-729.

Gleeson, P., Steuber, V., and Silver, R. A. (2007). neuroConstruct: a tool for modeling networks of neurons in 3D space. Neuron 54, 219-235.

Golgi, C. (1883). Sulla fina anatomia degli organi centrali del sistema nervoso IV. Sulla fina anatomia delle circonvoluzioni cerebellari. Riv. Sper. Freniatr. Med. Leg. Alien. Ment. 9, 1-17.

Gutfreund, Y., Yarom, Y., and Segev, I. (1995). Subthreshold oscillations and resonant frequency in guinea-pig cortical neurons: physiology and modelling. J. Physiol. (Lond.) 483(Pt 3), 621-640.

Hámori, J., and Somogyi, J. (1983). Differentiation of cerebellar mossy fiber synapses in the rat: a quantitative electron microscope study. J. Comp. Neurol. 220, 365-377.

Hartmann, M. J., and Bower, J. M. (1998). Oscillatory activity in the cerebellar hemispheres of unrestrained rats. J. Neurophysiol. 80, 1598-1604.

Harvey, R. J., and Napper, R. M. A. (1991). Quantitative studies of the mammalian cerebellum. Prog. Neurobiol. 36, 437-463. 
Häusser, M., and Clark, B. A. (1997). Tonic synaptic inhibition modulates neuronal output pattern and spatiotemporal synaptic integration. Neuron 19, 665-678.

Holt, G. R., Softky, W. R., Koch, C., and Douglas, R. J. (1996). Comparison of discharge variability in vitro and in vivo in cat visual cortex neurons. $J$. Neurophysiol. 75, 1806-1814.

Ito, M. (2006). Cerebellar circuitry as a neuronal machine. Prog. Neurobiol. 78, 272-303.

Izhikevich, E. M., and Edelman, G. M. (2008). Large-scale model of mammalian thalamocortical systems. Proc. Natl. Acad. Sci. U.S.A. 105, 3593-3598.

Jaeger, D., De Schutter, E., and Bower, J. M. (1997). The role of synaptic and voltage-gated currents in the control of Purkinje cell spiking: a modeling study. J. Neurosci. 17, 91-106.

Jakab, R. L., and Hámori, J. (1988). Quantitative morphology and synaptology of cerebellar glomeruli in the rat. Anat. Embryol. 179, 81-88.

Jörntell, H., and Ekerot, C. F. (2006). Properties of somatosensory synaptic integration in cerebellar granule cells in vivo. J. Neurosci. 26, 11786-11797.

Kanichay, R. T., and Silver, R. A. (2008). Synaptic and cellular properties of the feedforward inhibitory circuit within the input layer of the cerebellar cortex. J. Neurosci. 28, 8955-8967.

Kase, M., Miller, D. C., and Noda, H. (1980). Discharges of Purkinje cells and mossy fibres in the cerebellar vermis of the monkey during saccadic eye movements and fixation. J. Physiol. (Lond.) 300, 539-555.

Klyachko, V. A., and Stevens, C. F. (2006). Excitatory and feed-forward inhibitory hippocampal synapses work synergistically as an adaptive filter of natural spike trains. PLoS Biol. 4, e207. doi:10.1371/journal.pbio.0040207.

Korbo, L., Andersen, B. B., Ladefoged, O. and Møller,A. (1993). Total numbers of various cell types in rat cerebellar cortex estimated using an unbiased stereological method. Brain Res. 609, 262-268.

Maex, R., and De Schutter, E. (1998). Synchronization of Golgi and granule cell firing in a detailed network model of the cerebellar granule cell layer. $J$. Neurophysiol. 80, 2521-2537.

Mapelli, J., and D'Angelo, E. (2007). The spatial organization of longterm synaptic plasticity at the input stage of cerebellum. J. Neurosci. 27, 1285-1296.

Mapelli, J., Gandolfi, D., and D'Angelo, E. (2010a). Combinatorial responses controlled by synaptic inhibition in the cerebellum granular layer. $J$. Neurophysiol. 103, 250-261.
Mapelli, J., Gandolfi, D., and D‘Angelo, E. (2010b). High-pass filtering and dynamic gain regulation enhance vertical bursts transmission along the mossy fiber pathway of cerebellum. Front. Cell. Neurosci. 4:14. doi:10.3389/fncel.2010.00014

Mapelli, L., Rossi, P., Nieus, T., and D'Angelo, E. (2009). Tonic activation of GABAB receptors reduces release probability at inhibitory connections in the cerebellar glomerulus. J. Neurophysiol. 101, 3089-3099.

Marr, D. (1969). A theory of cerebellar cortex. J. Physiol. (Lond.) 202, 437-470.

Medina, J. F., and Mauk, M. D. (2000). Computer simulation of cerebellar information processing. Nat. Neurosci. 3, 1205-1211.

Misra, C., Brickley, S. G., Farrant, M., and Cull-Candy, S.G. (2000). Identification of subunits contributing to synaptic and extrasynaptic NMDA receptors in Golgi cells of the rat cerebellum. J. Physiol. (Lond.) 524, 147-162.

Mitchell, S. J., and Silver, R. A. (2000a). Glutamate spillover suppresses inhibition by activating presynaptic mGluRs. Nature 404, 498-502.

Mitchell, S. J., and Silver, R. A. (2000b). GABA spillover from single inhibitory axons suppresses low-frequency excitatory transmission at the cerebellar glomerulus. J. Neurosci. 20, 8651-8658.

Mitchell, S. J., and Silver, R. A. (2003). Shunting inhibition modulates neuronal gain during synaptic excitation. Neuron 38, 433-445.

Nieus, T., Sola, E., Mapelli, J., Saftenku, E., Rossi, P., and D'Angelo, E. (2006). LTP regulates burst initiation and frequency at mossy fiber-granule cell synapses of rat cerebellum: experimental observations and theoretical predictions. J. Neurophysiol. 95, 686-699.

Palay, S. L., and Chan-Palay, V. (1974). Cerebellar Cortex. New York: Springer-Verlag.

Palkovits, M., Magyar, P., and Szentàgothai, J. (1971). Quantitative histological analysis of the cerebellar cortex in the cat. II. Cell numbers and densities in the granular layer. Brain Res. 32, 15-30.

Palkovits, M., Magyar,P., and Szentágothai, J. (1972). Quantitative histological analysis of the cerebellar cortex in the cat. IV.Mossy fiber-Purkinje cell numerical transfer. Brain Res. 45, 15-29.

Pellerin, J. P., and Lamarre, Y. (1997). Local field potential oscillations in primate cerebellar cortex during voluntary movement. J. Neurophysiol. 78, 3502-3507.

Ramón y Cajal, S. (1887, 1889, 1904). Textura del sistema nervioso del hombrey delosvertebrados (3volumenes).Madrid: Imprenta y Librería de Nicolás Moya.

Rancz, E. A., Ishikawa, T., Duguid, I. Chadderton, P., Mahon, S., and Häusser, M. (2007). High-fidelity transmission of sensory information by single cerebellar mossy fibre boutons. Nature 450, 1245-1248.

Roggeri, L., Rivieccio, B., Rossi, P., and D’Angelo, E. (2008). Tactile stimulation evokes long-term synaptic plasticity in the granular layer of cerebellum. J. Neurosci. 28, 6354-6359.

Ros, H., Sachdev, R. N., Yu, Y., Sestan, N., and McCormick, D. A. (2009). Neocortical networks entrain neuronal circuits in cerebellar cortex. $J$. Neurosci. 29, 10309-10320.

Rossi, D. J., and Hamann, M. (1998). Spillover-mediated transmission at inhibitory synapses promoted by high affinity alpha6 subunit GABAA receptors and glomerular geometry. Neuron 20, 783-795.

Saviane, C., and Silver, R. A. (2006). Fast vesicle reloading and a large pool sustain high bandwidth transmission at a central synapse. Nature 439, 983-987.

Sola, E., Prestori, F., Rossi, P., Taglietti, V. and D'Angelo, E. (2004). Increased neurotransmitter release during longterm potentiation at mossy fibre-granule cell synapses in rat cerebellum. $J$. Physiol. (Lond.) 2004 557, 843-861.

Solinas, S., Forti, L., Cesana, E., Mapelli, J., De Schutter, E, and D'Angelo, E. (2007a). Computational reconstruction of pacemaking and intrinsic electroresponsiveness in cerebellar golg cells. Front. Cell. Neurosci. 1:2. doi: 10.3389/neuro.03.002.2007.

Solinas, S., Forti, L., Cesana, E., Mapelli, J., De Schutter, E, and D'Angelo, E. (2007b). Fast-reset of pacemaking and theta-frequency resonance patterns in cerebellar golgi cells: simulations of their impact in vivo. Front. Cell. Neurosci. 1:4 doi: 10.3389/neuro.03.004.2007.

Sultan, F. (2001). Distribution of mossy fiber rosettes in the cerebellum of cat and mice: evidence for a parasagittal organization at the single fiber level. Eur. J. Neurosci. 13, 2123-2130.

Sultan, F., and Heck, D. (2003). Detection of sequences in the cerebellar cortex: numerical estimate of the possible number of tidal-wave inducing sequences represented. J. Physiol. (Paris) 97, 591-600.

Traub, R. D., and Llinas, R. (1979). Hippocampal pyramidal cells: significance of dendritic ionic conductances for neuronal function and epileptogenesis. J. Neurophysiol. 42, 476-496.

Traub, R. D., Wong, R. K., Miles, R., and Michelson, H. (1991). A model of a CA3 hippocampal pyramidal neuron incorporating voltage-clamp data on intrinsic conductances. J. Neurophysiol. 66, 635-650.

Tyrrell, T., and Willshaw, D. (1992). Cerebellar cortex: its simulation and the relevance of Marr's theory. Philos. Trans. R. Soc. Lond., B, 336, 239-257.

Van Kan, P. L., Horn, K. M., and Gibson, A. R. (1994). The importance of hand use to discharge of interpositus neurones of the monkey. J. Physiol. (Lond.) 480, 171-190.

Van Kan, P. L., Houk, J. C., and Gibson, A. R. (1993). Output organization of intermediate cerebellum of the monkey. J. Neurophysiol. 69, 57-73.

Vanier, M. C., and Bower, J. M. (1999). A comparative survey of automated parameter-search methods for compartmental neural models. J. Comput. Neurosci. 7, 149-171.

Vos, B. P., Volny-Luraghi, A., and De Schutter, E. (1999). Cerebellar Golgi cells in the rat: receptive fields and timing of responses to facial stimulation. Eur. J. Neurosci. 11, 2621-2634.

Vos, B. P., Volny-Luraghi,A., Maex, R., and De Schutter, E. (2000). Precise spike timing of tactile-evoked cerebellar Golgi cell responses: a reflection of combined mossy fiber and parallel fiber activation? Prog. Brain Res. 124, 95-106.

Wang, X., Chen, G., Gao, W., and Ebner, T.J. (2009). Parasagittal organization of cerebellar cortex, parallel fibers and synaptic plasticity. SfN Abstract 319.10

Wu, H. S., Sugihara, I., and Shinoda, Y. (1999). Projection patterns of single mossy fibers originating from the lateral reticular nucleus in the rat cerebellar cortex and nuclei. J. Comp. Neurol. 411, 97-118.

Conflict of Interest Statement: The authors declare that the research was conducted in the absence of any commercial or financial relationships that could be construed as a potential conflict of interest.

Received: 01 August 2009; paper pending published: 13 November 2009; accepted: 18 March 2010; published online: 14 May 2010.

Citation: Solinas S, Nieus T and D'Angelo $E$ (2010) A realistic large-scale model of the cerebellum granular layer predicts circuit spatio-temporal filtering properties. Front. Cell. Neurosci. 4:12. doi: 10.3389/fncel.2010.00012

Copyright (c) 2010 Solinas, Nieus and D'Angelo. This is an open-access article subject to an exclusive license agreement between the authors and the Frontiers Research Foundation, which permits unrestricted use, distribution, and reproduction in any medium, provided the original authors and source are credited. 